


\title{
MOVED TO VOTE: THE LONG-RUN EFFECTS OF NEIGHBORHOODS ON POLITICAL
} PARTICIPATION

\author{
Eric Chyn \\ Kareem Haggag
}

We thank Paul Westscott of L2 for providing technical assistance. We are grateful to Erzo Luttmer for helpful comments and suggestions. Chyn thanks Brian Jacob for his help in accessing the data for this project.

(C) 2019 by Eric Chyn and Kareem Haggag. All rights reserved. Short sections of text, not to exceed two paragraphs, may be quoted without explicit permission provided that full credit, including $\odot$ notice, is given to the source. 
Moved to Vote: The Long-Run Effects of Neighborhoods on Political Participation

Eric Chyn and Kareem Haggag

November 2019

JEL No. D72,H75,I38,J13,R23,R38

\begin{abstract}
How does one's childhood neighborhood shape political engagement later in life? We leverage a natural experiment that moved children out of disadvantaged neighborhoods to study effects on their voting behavior more than a decade later. Using linked administrative data, we find that children who were displaced by public housing demolitions and moved using housing vouchers are 12 percent (3.3 percentage points) more likely to vote in adulthood, relative to their nondisplaced peers. We argue that this result is unlikely to be driven by changes in incarceration or in their parents' outcomes, but rather by improvements in education and labor market outcomes, and perhaps by socialization. These results suggest that, in addition to reducing economic inequality, housing assistance programs that improve one's childhood neighborhood may be a useful tool in reducing inequality in political participation.
\end{abstract}

Eric Chyn

Department of Economics

Dartmouth College

6106 Rockefeller Hall

Hanover, NH 03755

and NBER

eric.t.chyn@dartmouth.edu

Kareem Haggag

Social and Decision Sciences

Carnegie Mellon University

Porter Hall 208-H

5000 Forbes Avenue

Pittsburgh, PA 15213

kareem.haggag@cmu.edu 


\section{Introduction}

A growing body of research shows that childhood neighborhoods exert a powerful influence on later-life economic outcomes (Kling et al., 2007; Chetty et al., 2014, 2016; Chyn, 2018; Chetty and Hendren, 2018a,b). It is also possible that neighborhoods generate additional benefits to society that are not reflected in earnings or education. Enhanced political participation is one important outcome potentially shaped by a person's childhood residence. Theory and prior empirical research suggest that neighborhoods could impact voting. For example, neighborhoods may shape voting through several intermediate channels that have been previously linked to political behavior, including income (Akee et al., 2018), education (Sondheimer and Green, 2010), and incarceration (White, 2019), as well as pathways related to shaping voting norms and pressures (Wolfinger and Rosenstone, 1980; Wilson, 1987).

Despite its potential importance, relatively little evidence speaks directly to the effects of childhood neighborhoods on later-life voting. Instead, an existing literature has focused on credibly estimating how adults are affected by their current neighborhoods. For example, Gay (2012) tracked adults who moved to lower poverty neighborhoods through the Moving to Opportunity (MTO) experiment, finding evidence of reduced voter turnout for these adults 7 to 10 years after the move. ${ }^{1}$ However, these findings for MTO adults may not be a good guide for understanding the effects of neighborhoods and poverty on the eventual voting behavior of children. ${ }^{2}$ Prior research demonstrates that conditions in childhood have distinct and large impacts on a number of longerrun outcomes (Garces et al., 2002; Chetty et al., 2011; Heckman et al., 2013; Chetty et al., 2016; Hoynes et al., 2016; Carrell et al., 2018; Bald et al., 2019).

This paper provides the first causal estimates of the impact of moving to higher opportunity neighborhoods during childhood on political behavior. We rely on a natural experiment created by public housing demolitions. During the 1990s, the Chicago Housing Authority (CHA) began selectively destroying high-rise public housing buildings that suffered from poor maintenance. House-

\footnotetext{
${ }^{1}$ Enos (2016) also studies adult political behavior and neighborhood conditions. Examining the same natural experiment that we consider, he studies how the out-migration of public housing residents (predominately minority and low-income households) affected voting patterns of white voters who lived in close proximity to housing projects.

${ }^{2}$ Gay (2012) recognizes that impacts of housing mobility programs may differ between adults and children. She motivates future research in asking, "Is it only the adults who are voting less, or does the negative treatment impact span generations? How have the children of MTO, particularly those who are now of voting age, fared?"
} 
holds who lived in buildings selected for demolition received housing vouchers and relocated to lower crime and higher income neighborhoods. Jacob (2004) and Chyn (2018) studied this same setting to estimate short-run effects on education and long-run effects on labor market activity, use of government assistance programs, and criminal arrests.

We compare long-run voting outcomes of children displaced by public housing demolition to their peers who lived in nearby public housing buildings that were not destroyed. This comparison estimates causal impacts of relocating from public housing if displaced and non-displaced children are similar prior to demolition. Institutional features of our setting support the plausibility of this assumption, and we provide statistical evidence that shows no detectable differences of displaced and non-displaced persons in terms of background characteristics.

We find that relocating to lower poverty areas due to public housing demolition has large and statistically significant impacts on measures of political participation. Our analysis is based on linking administrative records for 5,933 displaced and non-displaced children to statewide voter registration records from Illinois. We find that displaced children are 2.3 to 2.8 percentage points (13 to 16 percent) more likely to vote in Presidential elections $(2008,2012,2016)$ and 3.3 percentage points (12 percent) more likely to vote in any general election (up to 2018). We also find evidence that part of this movement is driven by new voters, with registration increasing by 2.0 percentage points (5 percent).

To consider the potential mechanisms driving the increased voter participation, we undertake several exercises. First, we examine impacts of demolition on incarceration, and show that demolition and relocation significantly lowered the likelihood of ever being incarcerated in adulthood by 2.5 percentage points (16 percent). However, we argue that incarceration is unlikely to explain the voting impacts. We make this argument both by calibrating relative to the best available evidence on the impact of incarceration on voting (White, 2019), and by examining patterns in treatment effect heterogeneity - we find that the impacts on voting are entirely driven by females, while the impacts on incarceration are driven by males. Second, we examine changes in parents' outcomes and find these are unlikely to drive the voting results, as the intervention had no significant impact on their voting behavior. Third, we argue that improvements in high school graduation and labor market outcomes (earnings and employment) in adulthood are plausible mechanisms, as Chyn (2018) shows that the effects of demolition on these outcomes are large and prior studies show that 
these outcomes affect voting (Sondheimer and Green, 2010; Akee et al., 2018). Finally, we discuss more psychological channels, such as potential changes in beliefs and norms that come with moving to a new neighborhood, though we are limited in the data that can shed light on these mechanisms.

This paper contributes to a large and important literature studying neighborhood effects. To the best of our knowledge, we are the first to provide credible estimates of the impact of neighborhood conditions experienced in childhood on long-run voting. Our results complement a number of recent studies that show childhood residence has important later-life impacts on earnings (Chetty et al., 2016; Chyn, 2018; Chetty and Hendren, 2018a,b), criminal behavior (Damm and Dustmann, 2014), and health (Kling et al., 2007).

Our results also serve as a contribution to research on the determinants of voting and political participation more broadly. Prior studies such as Akee et al. (2018) and Holbein (2017) study how family income and interventions that foster non-cognitive skills affect political participation. We complement their results in demonstrating the importance of early-life conditions for voting. Our work is distinguished by the fact that the neighborhood intervention we study has no impacts on parental income and does not directly target skills of children.

We conclude by noting that this paper's findings have implications for public policy. Our results indicate that moving to higher opportunity areas generates externalities by increasing the level of citizens' involvement in the political process later in life. This may affect the distribution of public expenditures, as prior research provides evidence that politicians are responsive to voters' preferences (Husted and Kenny, 1997; Lott and Kenny, 1999; Cascio and Washington, 2014; Brunner et al., 2013; Fujiwara, 2015). Thus, by reducing political inequality, housing programs that help low-income families relocate could generate even further reductions in economic inequality. This may be particularly relevant given that policymakers have recently created new housing counseling programs (e.g., the Creating Moves to Opportunity program in Seattle and King County) and initiated reforms to housing voucher payment caps (e.g., Washington DC) as a means of encouraging low-income families to move to higher income neighborhoods (see Bergman et al. (2019) and Aliprantis et al. (2019)).

The paper proceeds as follows. Section 2 describes the public housing demolitions and data. Section 3 outlines the empirical strategy and provides evidence for the underlying assumptions. Section 4 reports the effects of displacement due to building demolition on long-term voting be- 
havior. Section 5 examines heterogeneous effects and considers mechanisms for the voting results. Section 6 concludes.

\section{Background and Data}

\subsection{History of Public Housing and Demolition in Chicago}

At the start of the 1990s, the Chicago Housing Authority (CHA) managed the third largest inventory of public housing buildings in the U.S. (Popkin et al., 2000). Many of these buildings were high-rises with more than 75 apartments. These units provided subsidized housing to households that had income at or below 50 percent of the household size-adjusted median local income. At this time, the vast majority of Chicago's public housing population was African American, and a large share were single-parent, female-headed households.

As noted in Jacob (2004) and Chyn (2018), the CHA started to demolish its public housing stock during the mid-1990s as a reaction to severe maintenance issues. The dilapidated housing conditions stemmed from age and consistently poor maintenance (Popkin et al., 2000). Importantly, federal funding facilitated demolition. ${ }^{3}$ In 1993, the U.S. Congress created the HOPE VI program, which provided funds for public housing demolition and revitalization. The CHA was one of the largest beneficiaries of the HOPE VI program, receiving nearly $\$ 160$ million in HOPE VI grants by 1998.

Due to the size of the public housing inventory in Chicago, the CHA could only finance the demolition of a relatively small number of buildings during the mid-1990s. In general, policymakers chose to close and destroy buildings that had the most severe maintenance issues. For example, pipes burst and caused flooding in several Robert Taylor project buildings in 1999. These buildings were subsequently closed and demolished.

When a building was closed for demolition, the CHA provided residents with Section 8 housing vouchers to subsidize relocation to private market housing. This voucher subsidy was equal to the difference between the family's rental contribution (30 percent of adjusted income) and the lesser of either the Fair Market Rent (FMR) or the price of rent. During the mid-1990s, the FMR was equal to the fortieth percentile of the local private market rent distribution. Families retained their

\footnotetext{
${ }^{3}$ The poor conditions in Chicago's public housing mirrored other major cities in the U.S. In 1992, a national commission found that 86,000 units of public housing in the U.S. were in need of major renovation or demolition (U.S. National Commission on Severely Distressed Public Housing, 1992).
} 
housing voucher as long as they remained eligible for housing assistance based on their income.

\subsection{Data Sources and Sample Construction}

We use records from multiple administrative sources to analyze the impact of public housing demolition on voting outcomes. We combine building records from the CHA and social assistance case files (1994-1997) from the Illinois Department of Human Services (IDHS) to create a sample of children who lived in public housing projects where demolitions occurred during the 1990s. We link this sample to the Illinois voter file (as of 2019) to obtain measures of registration and voting. ${ }^{4}$

Our analysis focuses on the same set of public housing projects and buildings studied in Chyn (2018). We study non-senior-citizen, high-rise projects that experienced demolitions during the initial wave of housing demolitions in Chicago during the $1995-1998$ period. ${ }^{5}$ We exclude the Cabrini Green and Henry Horner projects due to evidence suggesting that building demolition could be correlated with unobserved tenant characteristics. The final public housing building sample contains 53 high-rise buildings located in 7 projects. The date when a building was closed is based on Jacob (2004). During the study period, there were 20 demolished (treated) buildings and 33 comparison (control group) buildings that did not close during the 1995-2000 period.

To create the sample of children, we link the demolished and comparison group buildings to social assistance records for welfare recipients based on address information. Specifically, the sample is the set of children living in welfare recipient households that have a street address matching a public housing building in the year prior to building closure for demolition. Focusing on the address in the year prior to demolition ensures that the sample definition is unrelated to the potential impact of demolition on welfare receipt. The sample contains 3,002 households with 5,933 children who are ages 5-18 at the time of displacement due to demolition. $6,7,8$

\footnotetext{
${ }^{4}$ Appendix B provides detailed discussion of the data sources, sample construction, and linking process.

${ }^{5}$ High-rise buildings are defined as having 75 or more units.

${ }^{6}$ Data on children less than age 5 in the year of demolition is not available. The sample created in Chyn (2018) contained children ages 5-18 in the year of demolition. Records for children less than age 5 were not retained because these children were too young to be in the labor market in 2009, which was the latest year contained in the employment data used in Chyn (2018). See Appendix B for details.

${ }^{7}$ As detailed in Appendix B, the sample of 5,933 children is the set who can be uniquely linked using first name, last name and date of birth. There are 202 children who have non-unique or missing information in terms of this matching set of variables, and we do not include them in our analysis sample.

${ }^{8}$ The social assistance data contain 5,677 distinct households (including those without children ages 5-18) who lived in public housing in the year before building closure. Since the sample of public housing buildings contains 7,770 individual apartments, this suggests that the assistance sample covers at least 73 percent of the households living in the demolition sample of buildings (assuming there are no vacant apartments).
} 
We merge the sample of public housing children to the Illinois voter file as of 2019 using name and date of birth. ${ }^{9}$ The voter file includes registration information for the full state, voter turnout in the 2000-2018 general and primary elections, and a modeled variable indicating the party of the voter. ${ }^{10}$ The last general election that we observe occurs in 2018, when the youngest and oldest children in the sample are 28 and 41 years old, respectively. All children are the minimum voting age (18) by 2008, which implies that we observe voting outcomes in at least six elections (three presidential elections) for every child. On average, children in our sample are eligible to vote in about eight elections (four presidential elections).

Finally, as in Chyn (2018), we use data on unemployment insurance earnings records (19952009) and arrest records (up to 2009) to obtain information on baseline (prior to demolition) and other long-run outcomes of children. ${ }^{11}$ We also link the sample to sentencing records (up to 2012) to measure incarceration as an additional long-run outcomes. In Section 5, we study these long-run outcomes to interpret the analysis of voting outcomes.

\section{Empirical Strategy}

We follow Jacob (2004) and Chyn (2018) to study the impact of demolition and neighborhood relocation on outcomes of children. Specifically, we compare children within the same public housing unit, but who lived in buildings that were either selected for demolition ("displaced" or "treatment") or were left standing ("non-displaced" or "comparison"). Under the assumption that demolition was quasi-randomly assigned across buildings within the same public housing unit, we can compare the displaced against the non-displaced to estimate causal effects.

For voting outcome $y_{i}$, we estimate the following linear equation to recover this reduced form

\footnotetext{
${ }^{9}$ We obtained the voter file from L2, a commercial data vendor that works with major political parties in the U.S. L2 obtained a snapshot of the voter file on July 1, 2019 directly from the Illinois Secretary of State office. Voting data from L2 has been used in prior research in political science (Velez and Newman, 2019; Yoder, 2019; Enamorado et al., 2019)

${ }^{10}$ Since Illinois does not record the party of a voter, L2 provides a modeled field based on voting in partisan primaries. Specifically, they use the most recent even year primary in which a voter cast a partisan ballot. For example, if an individual voted in the Democrat primary in 2018 and the Republican primary in 2016, they will be recorded as a Democrat. If the voter has participated in no primaries, then they will be recorded as Non-Partisan.

${ }^{11}$ For the analysis of these long-run outcomes, we rely on data for the full sample of 6,135 children ages 5-18 created for Chyn (2018).
} 
impact of displacement due to demolition and relocation:

$$
y_{i}=\alpha+\beta D_{b(i)}+X_{i}^{\prime} \theta+\phi_{p(i)}+\epsilon_{i}
$$

where $i$ is an individual, and the indices $b(i)$ and $p(i)$ are the building and project for individual $i$. The term $\phi_{p(i)}$ is a set of project fixed effects. The vector $X_{i}$ is a set of control variables (i.e., gender and race) included to improve precision. The dummy variable $D_{b(i)}$ takes a value of 1 if an individual lived in a building slated for demolition during the mid-1990s. We cluster standard errors at the building level. The main parameter of interest is $\beta$, which captures the net impact of demolition and relocation on children's outcomes. In Section 3.2 below, we analyze post-demolition household location to aid interpretation of this reduced form parameter.

\subsection{Comparing Treatment and Control Individuals Prior to Demolition}

Estimates of $\beta$ have a causal interpretation if we assume that CHA's selection of buildings for demolition was unrelated to the characteristics of children. The historical evidence suggests this condition is plausible because maintenance issues were a driving concern when the CHA selected buildings for demolition. In addition, residents living in different buildings within the same project should have similar characteristics. This stems from the fact that the tenant allocation process restricts choice among households living in public housing. Most families spent years on a public housing wait list before receiving an offer to live in public housing. As a result, many accepted the first available unit that was offered to them.

In addition to the context, we follow Jacob (2004) and Chyn (2018) by providing statistical evidence for our identifying assumption by testing for differences between displaced and non-displaced residents for a range of pre-demolition characteristics. Table 1 provides support for our assumption of balance. We regress child and adult (parent) characteristics in the year before demolition on a dummy variable for living in a treated (i.e., later demolished) building and a set of project fixed effects following Equation 1. Column 1 reports means for the outcomes for the non-displaced children in our sample, while Column 2 shows the mean difference between displaced and non-displaced children within a project (i.e., the coefficient from the regression). We find no statistically significant differences across age or gender. Moreover, we observe no differences in pre-demolition juvenile 
arrests for the sub-sample $(2,069)$ of individuals who move after age 13 (the first age at which we observe arrests). Finally, we find no differences in schooling measures (enrollment, reading scores, math scores) for the sub-sample $(5,250)$ of individuals who move at or after age 7 (i.e., the sample from Chyn (2018)for which schooling outcomes are reported). ${ }^{12}$ By construction, we do not observe a baseline measure of our primary outcome (voting), as individuals are unable to vote before age 18. However, the fact that children are balanced on demographics, schooling, and crime outcomes is suggestive that they are also balanced on unobserved measures related to future voting behavior. Finally, since we will also examine parent voting outcomes in Section 5, we show in Column 5 that the parents of the children in our sample are also balanced on gender, labor market, and crime measures, though the displaced are slightly older (about 0.7 years older, relative to the average age of 31 in the non-displaced group).

\subsection{Relocation After Demolition}

The interpretation of $\beta$ from Equation 1 depends on the type of relocation experienced by displaced households. The demolitions and resulting housing vouchers led to increased housing choice for displaced households, and we use address histories based on social assistance case files to show that it induced individuals to move to less-disadvantaged neighborhoods. In Figure 1, we compare the neighborhood characteristics of the displaced and non-displaced children in the years leading up to and following the demolitions. We only observe addresses in the post demolition years for a subset of the full set of 3,002 households (containing the 5,993 children). For example, in the third year after demolition, we have address information for 2,297 of the full set of households with children. In Panel A of Figure 1, we show that this data incompleteness is balanced across the two groups in all years. Consistent with our identification argument, we find consistently no pre-trends in the years leading up to the demolition in terms of any neighborhood characteristics.

After demolition, Figure 1 shows statistically significant declines in the neighborhood fraction black (Panel B), poverty rate (Panel C) and violent crime rate (Panel D) in the years immediately following the demolitions. The short-run differences attenuate to zero within 10 years of the demolition, due to the gradual movement of non-displaced (control) households out of public housing. In Appendix Table A1, we report differences across these outcomes three years after

\footnotetext{
${ }^{12}$ The data on schooling outcomes is not available for this study.
} 
demolition, and find that the effects on neighborhood poverty and crime are large relative to the non-displaced household mean. As one point of comparison, the magnitude of the effects on the poverty rate is similar to the impact for the Section 8 treatment group in the MTO experiment. In Appendix Figure A1, we summarize the change experienced over time, by plotting densities of duration-weighted neighborhood poverty rates (i.e., averages over all the locations a household lived since displacement). Almost 60 percent of the displaced households lived in neighborhoods with poverty rates greater than 40 percent, which is the threshold for classification as an extreme poverty neighborhood, whereas 85 percent of the non-displaced households remained in extreme poverty neighborhoods through this period.

\subsection{Attrition and Spillovers}

Finally, this section considers two possible threats to identification and the interpretation of our estimates: attrition and spatial spillovers. Following Chyn (2018), Appendix Table A2 reports analysis based on the approach by Grogger (2013) to create proxy measures of attrition. ${ }^{13}$ The results show no evidence of differential attrition for the voting sample of children. In addition, another concern is that the demolition could have affected the long-term political participation of the control group. This spillover threat seems particularly plausible if the mechanism by which demolition affects participation is a psychological channel such as conveying a message about the quality of government services or encouraging a feeling of powerlessness (Baicker and Finkelstein, 2018; Soss, 1999; Schneider and Ingram, 1993). Such an "interpretive effect" may operate, as the control group would see homes similar to their own demolished, but would be unable to move through the housing vouchers made available to their neighbors.

To test for this threat, we assume that social interactions between buildings (and thus, spillovers) are decreasing with distance, and compare children who lived in control group buildings close to the demolished ones with those in the control group who lived further away. Formally, we implement this test by augmenting Equation 1 with additional indicators for living in a control building that

\footnotetext{
${ }^{13}$ The measure of attrition is based on observing terminal runs of zeros in administrative data. See Appendix $\mathrm{C}$ for details on the measure that we construct.
} 
is adjacent to a demolition building:

$$
y_{i}=\alpha+\beta^{\prime} D_{b(i)}+\pi N_{b(i)}+X_{i}^{\prime} \theta+\psi_{p(i)}+\epsilon_{i}
$$

where $N_{b(i)}$ is an indicator that a public housing building borders (is adjacent to) a demolitiontargeted building. The omitted group in the regression is the set of children living in stable buildings located farther away from a demolished building. Appendix Table A3 reports results that show that we find no evidence of spillovers given that the analysis fails to reject the null $\pi=0$ across voting outcomes, and the estimates of $\widehat{\pi}$ are generally small in magnitude. ${ }^{14}$

\section{Results}

We've shown that the demolition and offer of housing vouchers led families to relocate to less disadvantaged neighborhoods - we now turn to whether this intervention translated into increased voter participation later in life. To do so, we estimate Equation 1 across a variety of voting-related outcome measures. Figure 2 reports estimates from this equation where the outcome variables correspond to each of the 6 general elections that we observe for all individuals in our sample (during 2008-2016). The blue bars display the control group means, while the red bars correspond to the estimated voting rates of the displaced. We see that voting rates are low - between 5 to 10 percent - across the midterm elections $(2010,2014,2018)$ and not statistically different between the groups. By contrast, we find a significant increase in voting across all three Presidential elections, where voting rates are much higher (e.g., 17.2 percent for the control group in the 2008 election) and we thus have more power to detect differences. Table 2 reports these regression point estimates. Displaced children are 2.3 (13 percent), 2.8 (16 percent) and 2.6 (15 percent) percentage points more likely to vote in the 2008, 2012 and 2016 Presidential Elections, respectively.

Since there is no a priori reason to focus on a specific election, we construct measures to summarize voting across our data. We draw on previous practice to motivate two primary types of measures. First, similar to Sondheimer and Green (2010) and Akee et al. (2018), we define binary variables indicating whether the individual ever voted in any general election we observe (2000-

\footnotetext{
${ }^{14}$ Moreover, we find the treatment effects of demolition and relocation (i.e., estimates of $\beta$ ) on voting are similar to the main results that we obtain with Equation 1.
} 
2018) or in any primary election we observe. Second, similar to Holbein (2017), we define a voting rate measure that is restricted to Presidential elections where we have power to detect effects specifically, this is a continuous measure of the proportion of eligible Presidential elections that the individual voted in. The denominator for the latter measure ranges from 3 eligible elections (for the youngest in our sample) to 5 eligible elections, with an average of 3.9 in our sample. We find that displaced individuals are 3.3 (12 percent) percentage points more likely to ever vote in a general election and 2.0 (14 percent) percentage points more likely to vote in a primary. Finally, summarizing across the presidential elections, we see that the displaced have a 2.7 (17 percent) percentage point increase in the share of elections in which they voted.

These increases in voter participation could be driven by new registrants or by increased participation of those who would be registered regardless. ${ }^{15}$ While it's possible that individuals may register and never vote, the fact that we find effects on the ever vote measure suggests this is not simply driven by movements on the intensive margin of voting. The estimates for the voter registration outcome corroborate this hypothesis: displaced children are 2.0 percentage points ( 5 percent) more likely to be registered. This suggests that a significant portion of the increase in voting may be driven by new voters. Finally, we break this down by partisanship. While Illinois does not record party information for voters, there are records on participation in partisan primaries. Based on this information, L2 created a measure of party affiliation that is based on the primary elections in which an individual voted. The results near the bottom of Table 2 show that we find that the new voters are those identified as Democrats, while there are smaller and not statistically significant effects on being identified as a Republican or Non-Partisan.

\section{$5 \quad$ Heterogeneity and Mechanisms}

There are several potential mechanisms through which moving children into more advantaged neighborhoods could increase their propensity to vote in adulthood. In this section, we consider the roles of incarceration, labor market outcomes, education, transmission of parent voting preferences, and more "psychological" channels (e.g. political socialization) that remain unobserved. As the first four are all post-treatment outcomes, we refrain from including them in our regressions because

\footnotetext{
${ }^{15}$ As noted in Section 5, this appears to be the case for the parents in our sample. Appendix Table A5 shows a significant increase in the registration likelihood (i.e., a 3 percentage point (7.7 percent) increase), though no statistically significant increases in their measures of voting.
} 
the strong assumptions required for mediation analysis are unlikely to hold. Instead, we examine patterns in these outcomes, their parallels to the voting results, and the prior literature to provide some suggestive evidence. We argue that our results are more consistent with being mediated by the education and labor market improvements, as well as socialization and norms, rather than following directly from incarceration or parental outcomes - though our conclusions here are limited by the data at hand.

\subsection{Incarceration}

We begin by considering the role of incarceration. Chyn (2018) found that children moved by the demolitions had fewer arrests for violent crimes - given this result, we use sentencing data (up to 2012) from the Illinois State Police to see if these arrest effects translated into a lower likelihood of incarceration. Incarceration could affect voting through several channels: disenfranchisement, incapacitation or discouragement. With respect to the first channel, roughly 6 million Americans were disenfranchised in 2016 due to current or past felony convictions (Sentencing Project, 2013). In many states, those convicted of a felony are unable to vote for periods of time after they are released from prison. Further, 11 states restrict voting even after an individual completes their full prison, probation, and parole sentence. Illinois falls into one of the less strict categories, as those convicted of a felony are only restricted from voting while serving their prison sentence. Outside of felony convictions, individuals in the prison system (e.g., those awaiting a trial in jail) may be legally allowed to vote, but in practice, that ability may be limited. We thus examine whether displaced individuals were less likely to be in prison during a given election, regardless of whether the crime was a felony. Appendix Table A4 shows the effect on being in prison over the entire post-demolition period (up to 2012) and during different election years. ${ }^{16}$ While demolition reduces the likelihood of ever being incarcerated, we see insignificant reductions in individual election years (i.e., a 0.7 percentage point decrease in 2008), which suggests that formal disenfranchisement is unlikely to explain the increases in voting across each of those elections (i.e., the 2.3 percentage point voting increase in 2008).

\footnotetext{
${ }^{16}$ We choose to use this coarse measure - rather than whether the individual is in prison specifically on Election Day - because the sentencing data do not have the exact dates of a sentence. Instead, we only observe the length of a sentence and the sentencing date. This may produce measurement error, and thus attenuate any effects we observe. By casting a relatively wide net around Election Day, we hope to balance this bias.
} 
Prior research by White (2019) suggests that incarceration may discourage individuals from voting, even in the absence of formal disenfranchisement. Focusing on misdemeanors that carry no formal consequences for voting eligibility, and instrumenting for incarceration using one's assigned courtroom's propensity to incarcerate, she finds that incarceration reduces the likelihood of voting in the subsequent Presidential election (after release) by 13 percentage points for Black defendants. Under relatively strong assumptions, we can use these causal estimates from Harris County to perform a back-of-the-envelope calibration of how the overall decrease in incarceration in our Chicago sample would translate into voting outcomes. Specifically, we observe a 2.5 percentage point reduction in the likelihood of ever being incarcerated across the full sample period (up to 2012). If we assume each of these individuals lowered their likelihood of ever voting by 13 percentage points, this would mean that the discouragement channel could explain less than 10 percent $(0.025 \times 13=0.325$ percentage points) of the overall 3.3 percentage point effect.

Perhaps even stronger evidence against this channel comes from the heterogeneity we observe in the main effects on voting and in the incarceration and arrest results. Figure 3 summarizes effects on voting and incarceration for various subgroups based on baseline characteristics. ${ }^{17}$ The estimated difference between displaced and non-displaced children is the center (line) in each box plotted for a given group. The top and bottom of each box represent effects that are one standard error above and below the point estimate, while the whiskers display the 95 percent confidence interval. We find that the effects on voting are entirely driven by females (a 6.4 percentage point increase in voting), and that the effects on incarceration are small and insignificant for females (a 1.2 percentage point decrease). Together these results suggest that, while we do observed reduced likelihood of incarceration (particularly for males), this outcome is unlikely to explain our results through either an incapacitation or discouragement channel.

\subsection{Parent Outcomes}

Displacement affected not just children, but also their parents. In this way, it is possible that the intervention could have increased parent voting, and that this voting preference was transmitted to their children. We find relatively weak evidence for this channel in Appendix Table A5. On the one hand, we find that parents are 3 percentage points ( 7 percent) more likely to be registered to vote

\footnotetext{
${ }^{17}$ Appendix Tables A6 and A7 report the point estimates and standard errors.
} 
as adults, an effect larger than what we find on children's registration likelihood (a 2 percentage point increase). On the other, there is a no detectable impact on the likelihood of ever voting in a general election (2000-2018) and a relatively precise null effect on the "vote share." The latter result contrasts to the significant effect on "vote share" for children (a 2.7 percentage point increase). This latter result is also consistent with evidence in Akee et al. (2018) showing that an unconditional cash transfer to parents had no effect on their voting share, but increased that of their children. While it is possible that parents' improved outcomes led them to shape the preferences of their children without necessarily changing their own voting behavior, Chyn (2018) finds that the displacement had no detectable impacts on parents' labor market outcomes, suggesting limited scope for this mechanism as well.

\subsection{Education}

Jacob (2004) provides a comprehensive analysis of the short-run impact of demolition on schooling outcomes. Notably, he found that displaced children do not attend better quality schools (as measured by test scores) and have higher achievement on standardized exams. In longer-run followup work, Chyn et al. (2017) found that displacement decreased the likelihood that children dropped out of high school by 5.1 percentage points ( 8 percent, relative to the control group mean of 63.1 percent) for those who moved while young (ages 7-12), but had no detectable effect on those who moved between when older (ages 13-18). This parallels the pattern of results for voting, where we find a large and significant (4.1 percentage points) effect on voting for those who moved while young (ages 5-11), and a smaller and insignificant effect for those who moved while older (1.8 percentage points) (as reported in Figure 3 and Appendix Table A6). This naturally raises the question of whether the effects on education are driving changes in voting. To get a sense of the magnitude of this channel, we turn to the prior literature estimating the causal effects of high school graduation on voter participation. Sondheimer and Green (2010) pooled results from three randomized education interventions that increased graduation rates (Perry Preschool, Project STAR, and IHAD) and linked to voting outcomes. Their pooled estimate suggests that high school graduation increases voting by 1.4 probits. Applying this optimistic estimate to our control group mean of 28.3 percent (ever voted), suggests that high school graduation alone could increase their turnout to 79.6 percent. Thus, this calibration suggests that roughly 80 percent $(0.051 \times(0.796-0.283)=2.6$ per- 
centage points) of the 3.3 percentage point effect could be explained through the education channel. If we instead use the bottom of their 90 percent confidence interval of their estimated effect $(0.51$ probits $)$, the education channel could explain roughly 30 percent $(0.051 \times(0.474-0.283)=1.0$ percentage points) of the effect.

\subsection{Labor and Income}

A fourth potential channel by which the move may have affected voting outcomes is through its' improvements in children's adult labor market outcomes as documented in Chyn (2018). Appendix Table A8 shows that displaced children are 3.7 percentage points more likely to be employed in adulthood. The effects on employment by gender and poverty status mirror the pattern that we see for voting (effects are larger for females and those who move away from higher-poverty neighborhoods). As shown in Figure 3 and Appendix Figure A2, we do find larger impacts on employment and earnings for older displaced children, which contrasts with the impacts on voting being driven by younger children. ${ }^{18}$

The effect of employment on voting behavior is not a priori obvious. On the one hand, employment increases the opportunity cost of voting, particularly for individuals in this income segment who may face limited schedule flexibility on Election Days. On the other, employment increases earnings and may affect one's social environment. As the prior literature does not - to our knowledge - provide causal evidence on the effects of employment on voting, we turn to the income and earnings channel. We find that displaced children earned an additional $\$ 549$ per year (15 percent increase) in adulthood (see Appendix Table A9). As noted in the introduction, the (largely correlational) literature on the effects of income on voting is mixed. A meta-analysis of 90 studies shows that half find income to be a significant predictor of voting, while the other half do not. Perhaps the only causal estimates of the effects of an unconditional cash transfer in the U.S. come from Akee et al. (2018). They find that a transfer of $\$ 4,700$ to parents increased later-life voting of children by 8 percentage point. While it's unclear how much this raised the earnings of children, it's plausible

\footnotetext{
${ }^{18}$ One key caveat for these results is that the labor market analysis is based on data up to 2009, while voting outcomes are measured up including elections up to 2018. This is important because prior research has documented that larger labor market impacts of relocating to better neighborhoods emerge during the mid-to-late 20s (when children have completed their education and transition to the labor market) (Chetty et al., 2016; Chyn, 2018). In this way, it is possible that effects of demolition on employment for young children grow in the years subsequent to 2009 , thereby potentially driving impacts on voting outcomes.
} 
that this was partly mediated through the earnings of the children in adulthood (they find much larger improvements in education, and argue this a likely mediator of the relationship as well).

\subsection{Psychological Channels}

Finally, the effects on voting may be mediated through a broad set of psychological channels, such as political socialization. That is, neighborhoods (via peers in school and work, neighbors, and other social influences) may change the value an individual receives from voting, either by shaping their perceptions of inclusion and empowerment, moving their beliefs about the efficacy of voting, or affecting the social pressures or benefits they face around voting (Wilson, 1987; Cohen and Dawson, 1993; Desmond and Travis, 2018). To be clear, these are not necessarily distinct or competing channels from those previously discussed - some of these psychological effects may be produced by the intermediate changes in income, education, or other outcomes. Ultimately, we have little data to shed light on these mechanisms, but provide some discussion nonetheless.

The Chicago Housing Authority's decision to demolish buildings and provide housing vouchers represents a substantive and salient act of government policy in the lives of their constituents. Prior work in political science posits that such policy may affect the way individuals perceive and interact with political institutions (Baicker and Finkelstein, 2018; Pierson, 1993; Campbell, 2012). These "interpretive effects" may result in positive or negative policy feedback. On the one hand, the demolitions could have conveyed the sense that government services are of low quality or encourage feelings of powerlessness (Baicker and Finkelstein, 2018; Soss, 1999; Schneider and Ingram, 1993). On the other, the move to better neighborhoods, facilitated through the government-provided vouchers, could have sent a message of inclusion that encourages participation; though prior work has theorized this channel to be present for universal programs rather than means-tested programs (Wilson, 1987; Skocpol, 1991). A body of empirical research, largely outside the U.S., has shown that means-tested programs, such as conditional cash transfer, may improve voter turnout (e.g., De La O (2013)). Within the U.S., Baicker and Finkelstein (2018) and Clinton and Sances (2018) find that Medicaid expansion led to positive, but temporary, improvements in voter turnout. By contrast, we find a persistent increase in voting many years later for the children in our sample, but no improvement for adults and a smaller improvement for older children. While it's possible that such interpretive effects operate differently for young children, this set of results suggest the 
standard account may not explain our results.

More broadly, a literature within political science has posited a key role for childhood in shaping political socialization, going back to at least Greenstein's (1965) focus on 9-13 year-olds. For

example, the "impressionable years" hypothesis posits that young people may have more malleable political behavior because their relevant attitudes and identities have yet to ossify by that point (Krosnick and Alwin, 1989; Sears and Funk, 1999). This is consistent with work showing that interest in politics is relatively stable and resistant to intervention after late adolescence (Prior, 2010, 2018). While some of this work focuses on intergenerational socialization (i.e., the learning of norms and values around voting from parents), socialization can be shaped by various institutions tied to a neighborhood including schools, church, media, peers and others. As noted above, and shown in Figure 3, we find larger effects for children who moved while younger (ages 5-11 vs. ages 12-18). This would be consistent with the early argument within this largely theoretical literature that, "the more important a political orientation is in the behavior of adults, the earlier it will be found in the learning of the child" (Greenstein, 1965; Akee et al., 2018). While it's likely that the economic channels have similarly more pronounced effects when received earlier, in line with Chetty et al. (2016) and Chetty and Hendren (2018a), it's also plausible that these could be operating indirectly through the psychological channels (e.g., a common set of norms and values, instilled earlier in childhood, leading to improved graduation and political participation). Ultimately, while these psychological channels are a compelling way that neighborhoods may shape political behavior, we can only speculate with the data at hand. Future work with survey data may be able to shed further light on these mechanisms.

\section{Conclusion}

To the best of our knowledge, this paper provides the first causal estimates of the impact of moving to higher opportunity neighborhoods on long-run voting behavior. Our evidence is based on a natural experiment in which public housing demolition in Chicago forced low-income households to relocate to lower-poverty areas using housing vouchers. We find that children displaced by demolition are 12 percent more likely to vote in adulthood, relative to their non-displaced peers.

Our findings complement recent work that provides credible evidence that childhood neigh- 
borhoods exert powerful influences over labor market outcomes (Chetty et al., 2016; Chyn, 2018; Chetty and Hendren, 2018a,b), crime (Damm and Dustmann, 2014), and health (Kling et al., 2007). Prior studies of long-run voting behavior suggest that these outcomes are potential mediators of the impacts that we detected. Based on an analysis of heterogeneous treatment effects across outcomes, we argue that our findings are unlikely be driven by changes in criminal justice outcomes (arrests or incarceration), but rather by improvements in education, labor market outcomes, or socialization. The evidence also suggests the effects are not mediated by changes in the political behavior or labor market outcomes of parents.

Finally, the voting impacts that we document have implications for public policy. Housing authorities and policymakers have introduced new housing counseling programs (e.g., the Creating Moves to Opportunity program in Seattle and King County) and reformed housing voucher payment caps (e.g., Washington DC) to encourage low-income families to relocate to higher income neighborhoods. An emerging set of studies has demonstrated that these types of reforms, particularly in terms of counseling, can successfully promote relocation to higher opportunity areas (Bergman et al., 2019; Aliprantis et al., 2019). Our results suggest that these policies may generate externalities in terms of increasing long-run involvement in the political process. This may be important for political outcomes given that prior research shows that politicians are responsive to the interests of their constituents. 


\section{References}

Akee, Randall, Copeland, William, Costello, E. Jane, Holbein, John and Simeonova, Emilia. (2018), Family Income and the Intergenerational Transmission of Voting Behavior: Evidence from an Income Intervention, NBER Working Paper 24770, National Bureau of Economic Research, Cambridge, MA.

Alex-Assensoh, Yvette. (1998), Neighborhoods, Family, and Political Behavior in Urban America: Political Behavior $\&$ Orientations, Routledge.

Aliprantis, Dionissi, Martin, Hal and Phillips, David. (2019), Landlords and Access to Opportunity, Working paper (Federal Reserve Bank of Cleveland) WP 19-02r, Federal Reserve Bank of Cleveland.

Baicker, Katherine and Finkelstein, Amy. (2018), The Impact of Medicaid Expansion on Voter Participation: Evidence from the Oregon Health Insurance Experiment, NBER Working Paper 25244, National Bureau of Economic Research.

Bald, Anthony, Chyn, Eric, Hastings, Justine S and Machelett, Margarita. (2019), The Causal Impact of Removing Children from Abusive and Neglectful Homes, NBER Working Paper 25419, National Bureau of Economic Research.

Bergman, Peter, Chetty, Raj, DeLuca, Stefanie, Hendren, Nathaniel, Katz, Lawrence F and Palmer, Christopher. (2019), Creating Moves to Opportunity: Experimental Evidence on Barriers to Neighborhood Choice, NBER Working Paper 26164, National Bureau of Economic Research.

Brunner, Eric, Ross, Stephen L. and Washington, Ebonya. (2013). 'Does Less Income Mean Less Representation?', American Economic Journal: Economic Policy 5(2), 53-76.

Campbell, Andrea Louise. (2012). 'Policy Makes Mass Politics', Annual Review of Political Science 15(1), 333-351.

Carrell, Scott E., Hoekstra, Mark and Kuka, Elira. (2018). 'The Long-Run Effects of Disruptive Peers', American Economic Review 108(11), 3377-3415.

Cascio, Elizabeth U. and Washington, Ebonya. (2014). 'Valuing the Vote: The Redistribution of Voting Rights and State Funds following the Voting Rights Act of 1965', The Quarterly Journal of Economics 129(1), 379-433.

Chetty, Raj, Friedman, John N., Hilger, Nathaniel, Saez, Emmanuel, Schanzenbach, Diane Whitmore and Yagan, Danny. (2011). 'How Does Your Kindergarten Classroom Affect Your Earnings? Evidence from Project Star', The Quarterly Journal of Economics 126(4), 1593-1660.

Chetty, Raj and Hendren, Nathaniel. (2018a). 'The Impacts of Neighborhoods on Intergenerational Mobility I: Childhood Exposure Effects*', The Quarterly Journal of Economics .

Chetty, Raj and Hendren, Nathaniel. (2018b). 'The Impacts of Neighborhoods on Intergenerational Mobility II: County-Level Estimates', The Quarterly Journal of Economics 133(3), 11631228 . 
Chetty, Raj, Hendren, Nathaniel and Katz, Lawrence F. (2016). 'The Effects of Exposure to Better Neighborhoods on Children: New Evidence from the Moving to Opportunity Experiment', American Economic Review 106(4), 855-902.

Chetty, Raj, Hendren, Nathaniel, Kline, Patrick and Saez, Emmanuel. (2014). 'Where is the Land of Opportunity? The Geography of Intergenerational Mobility in the United States', The Quarterly Journal of Economics 129(4), 1553-1623.

Chyn, Eric. (2018). 'Moved to Opportunity: The Long-Run Effects of Public Housing Demolition on Children', The American Economic Review 108(10), 3028-3056.

Chyn, Eric, Jacob, Brian and Ludwig, Jens. (2017), The Impact of Public Housing Demolition on Long-Run Education Outcomes, Unpublished.

Clinton, Joshua D. and Sances, Michael W. (2018). 'The Politics of Policy: The Initial Mass Political Effects of Medicaid Expansion in the States', American Political Science Review 112(1), 167-185.

Cohen, Cathy J. and Dawson, Michael C. (1993). 'Neighborhood Poverty and African American Politics', The American Political Science Review 87(2), 286-302.

Damm, Anna Piil and Dustmann, Christian. (2014). 'Does Growing Up in a High Crime Neighborhood Affect Youth Criminal Behavior?', American Economic Review 104(6), 1806-1832.

De La O, Ana L. (2013). 'Do Conditional Cash Transfers Affect Electoral Behavior? Evidence from a Randomized Experiment in Mexico', American Journal of Political Science 57(1), 1-14.

Desmond, Matthew and Travis, Adam. (2018). 'Political Consequences of Survival Strategies among the Urban Poor', American Sociological Review 83(5), 869-896.

Enamorado, Ted, Fifield, Benjamin and Imai, Kosuke. (2019). 'Using a Probabilistic Model to Assist Merging of Large-Scale Administrative Records', p. 19.

Enos, Ryan D. (2016). 'What the Demolition of Public Housing Teaches Us about the Impact of Racial Threat on Political Behavior', American Journal of Political Science 60(1), 123-142.

Erikson, Robert S. (2015). 'Income Inequality and Policy Responsiveness', Annual Review of Political Science 18(1), 11-29.

Fujiwara, Thomas. (2015). 'Voting Technology, Political Responsiveness, and Infant Health: Evidence From Brazil', Econometrica 83(2), 423-464.

Garces, Eliana, Thomas, Duncan and Currie, Janet. (2002). 'Longer-Term Effects of Head Start', The American Economic Review 92(4), 999-1012.

Gay, Claudine. (2012). 'Moving to Opportunity: The Political Effects of a Housing Mobility Experiment', Urban Affairs Review 48(2), 147-179.

Greenstein, Fred. (1965), Children and Politics, Yale University Press, New Haven, CT.

Grogger, Jeffrey. (2013), Bounding the Effects of Social Experiments: Accounting for Attrition in Administrative Data, NBER Working Paper 18838, National Bureau of Economic Research. 
Heckman, James, Pinto, Rodrigo and Savelyev, Peter. (2013). 'Understanding the Mechanisms Through Which an Influential Early Childhood Program Boosted Adult Outcomes', American Economic Review 103(6), 2052-2086.

Holbein, John B. (2017). 'Childhood Skill Development and Adult Political Participation', American Political Science Review 111(3), 572-583.

Hoynes, Hilary, Schanzenbach, Diane Whitmore and Almond, Douglas. (2016). 'LongRun Impacts of Childhood Access to the Safety Net', American Economic Review 106(4), 903934.

Husted, Thomas A. and Kenny, Lawrence W. (1997). 'The Effect of the Expansion of the Voting Franchise on the Size of Government', Journal of Political Economy 105(1), 54-82.

Jacob, Brian A. (2004). 'Public Housing, Housing Vouchers, and Student Achievement: Evidence from Public Housing Demolitions in Chicago', The American Economic Review 94(1), 233-258.

Kling, Jeffrey R., Liebman, Jeffrey B. and Katz, Lawrence F. (2007). 'Experimental Analysis of Neighborhood Effects', Econometrica 75(1), 83-119.

Krosnick, Jon A and Alwin, Duane E. (1989). 'Aging and Susceptibility to Attitude Change'.

Lott, Jr., John R. and Kenny, Lawrence W. (1999). 'Did Women's Suffrage Change the Size and Scope of Government?', Journal of Political Economy 107(6), 1163-1198.

Pierson, Paul. (1993). 'When Effect Becomes Cause: Policy Feedback and Political Change', World Politics 45(4), 595-628.

Popkin, Susan J, Gwiasda, Victoria, Olson, Lynn, Rosenbaum, Dennis and Buron, Larry. (2000), The Hidden War: Crime and the Tragedy of Public Housing in Chicago, Rutgers University Press, New Brunswick, NJ.

Prior, Markus. (2010). 'You've Either Got It or You Don't? The Stability of Political Interest over the Life Cycle', The Journal of Politics 72(3), 747-766.

Prior, Markus. (2018), Hooked: How Politics Captures People's Interest, Cambridge University Press. Google-Books-ID: 8492DwAAQBAJ.

Schneider, Anne and Ingram, Helen. (1993). 'Social Construction of Target Populations: Implications for Politics and Policy', The American Political Science Review 87(2), 334-347.

Sears, David O. and Funk, Carolyn L. (1999). 'Evidence of the Long-Term Persistence of Adults' Political Predispositions', The Journal of Politics 61(1), 1-28.

Sentencing Project. (2013), Felony Disenfranchisement: A Primer, Technical report.

Skocpol, Theda. (1991), Targeting Within Universalism: Politically Viable Policies to Combat Poverty in the United States, in Christopher Jencks and Peterson Paul., eds, 'The Urban Underclass', The Brookings Institution, Washington, D.C.

Sondheimer, Rachel Milstein and Green, Donald P. (2010). 'Using Experiments to Estimate the Effects of Education on Voter Turnout', American Journal of Political Science 54(1), 174-189. 
Soss, Joe. (1999). 'Lessons of Welfare: Policy Design, Political Learning, and Political Action', American Political Science Review 93(2), 363-380.

U.S. Census. (2018), Table 4c. Reported Voting and Registration by Age, for States: November 2018, Technical report.

U.S. National Commission on Severely Distressed Public Housing. (1992), Final Report of the National Commission on Severely Distressed Public Housing, Technical report, Washington, D.C.

Velez, Yamil Ricardo and Newman, Benjamin J. (2019). 'Tuning In, Not Turning Out: Evaluating the Impact of Ethnic Television on Political Participation', American Journal of Political Science 63(4), 808-823.

White, Ariel. (2019). 'Misdemeanor Disenfranchisement? The Demobilizing Effects of Brief Jail Spells on Potential Voters', American Political Science Review 113(2), 311-324.

Wilson, William J. (1987), The Truly Disadvantaged: The Inner City, the Underclass, and Public Policy, University of Chicago Press.

Wolfinger, Raymond and Rosenstone, Steven. (1980), Who Votes?, Yale University Press.

Yoder, Jesse. (2019), Does Property Ownership Lead to Participation in Local Politics? Evidence from Property Records and Meeting Minutes. 


\section{$7 \quad$ Figures and Tables}

Figure 1: Impacts of Demolition and Relocation on Neighborhood Characteristics Over Time

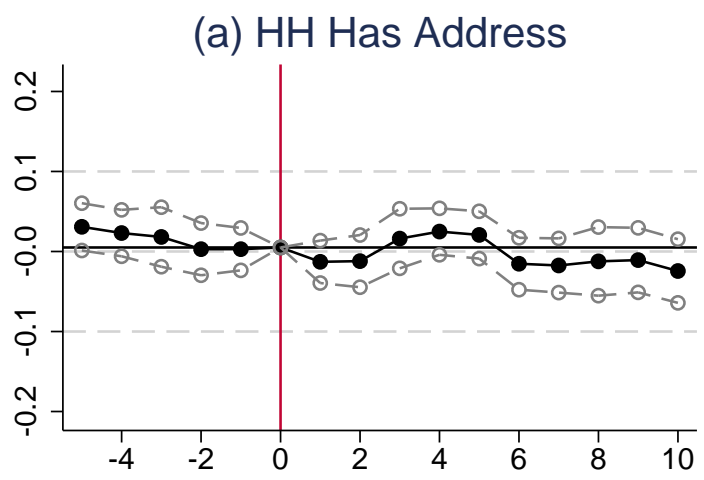

(b) Black (Pct. Points)

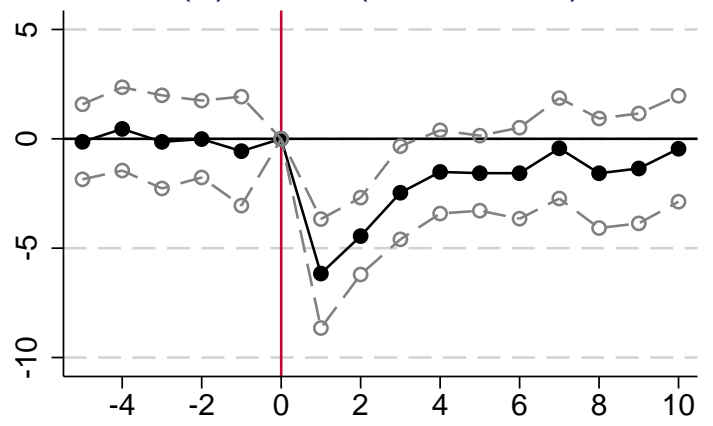

(c) Below Poverty (Pct. Points)

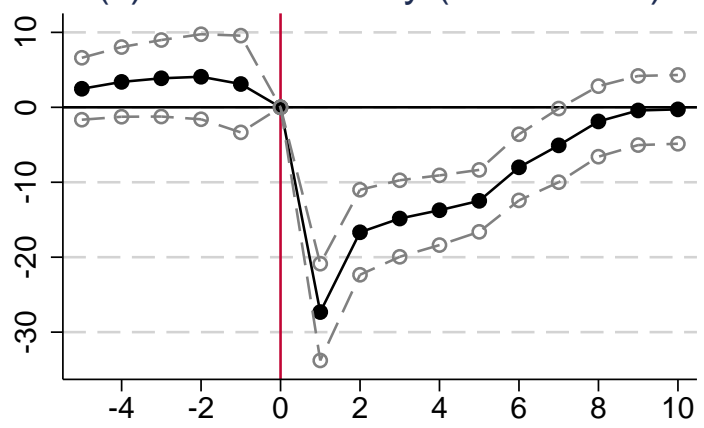

(d) Violent Crime per 10k

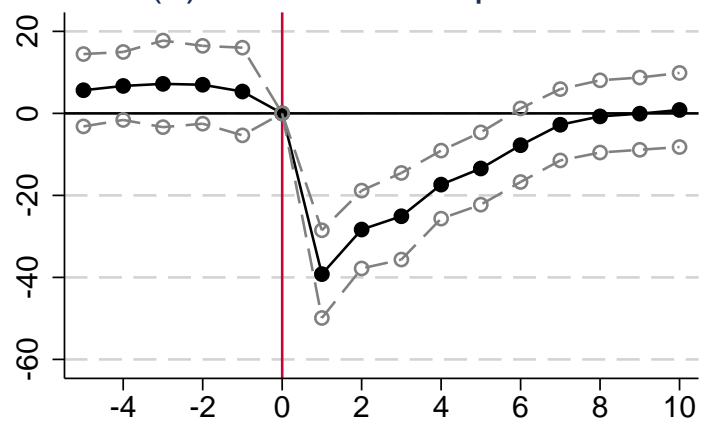

Notes: Panels show impacts of demolition on neighborhood characteristics over time. The unit of analysis is a household with at least one child. Neighborhood characteristics are from Census data. Location is measured using address data from IDHS social assistance files. The $x$-axis measures the number of years since relocation due to demolition. Each point in a panel is an estimate of the difference between displaced and non-displaced households in a given period. Robust standard errors are clustered at the public housing building level. 
Figure 2: Impacts of Demolition and Relocation on General Election Voting

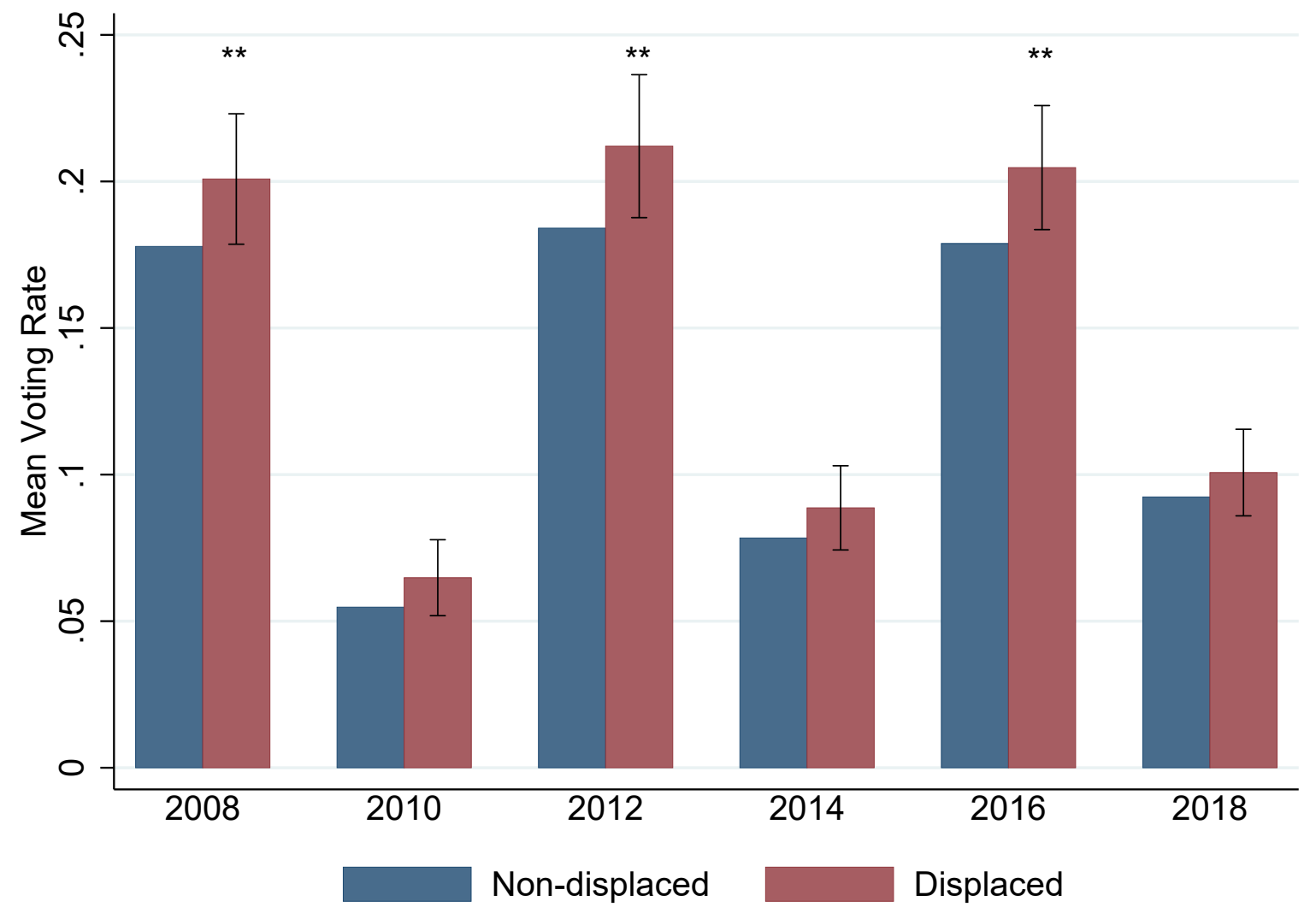

Notes: Bars display voting rates for the 2008-2016 general elections. The navy (left) bar for each election displays the mean voting rate for non-displaced (control) children. The maroon (right) bar for each election displays the estimated voting rate for displaced children. The estimate for displaced children is based on analysis for each outcome using Equation 1. The black bars on the maroon (right) bar illustrate the 95-percent confidence interval for each general election outcome. Statistical significance is denoted by: ${ }^{*} p<0.10,{ }^{* *} p<0.05$ and ${ }^{* * *} p<0.01$. 
Figure 3: Impacts of Demolition and Relocation on Voting, Earnings and Incarceration by Subgroup
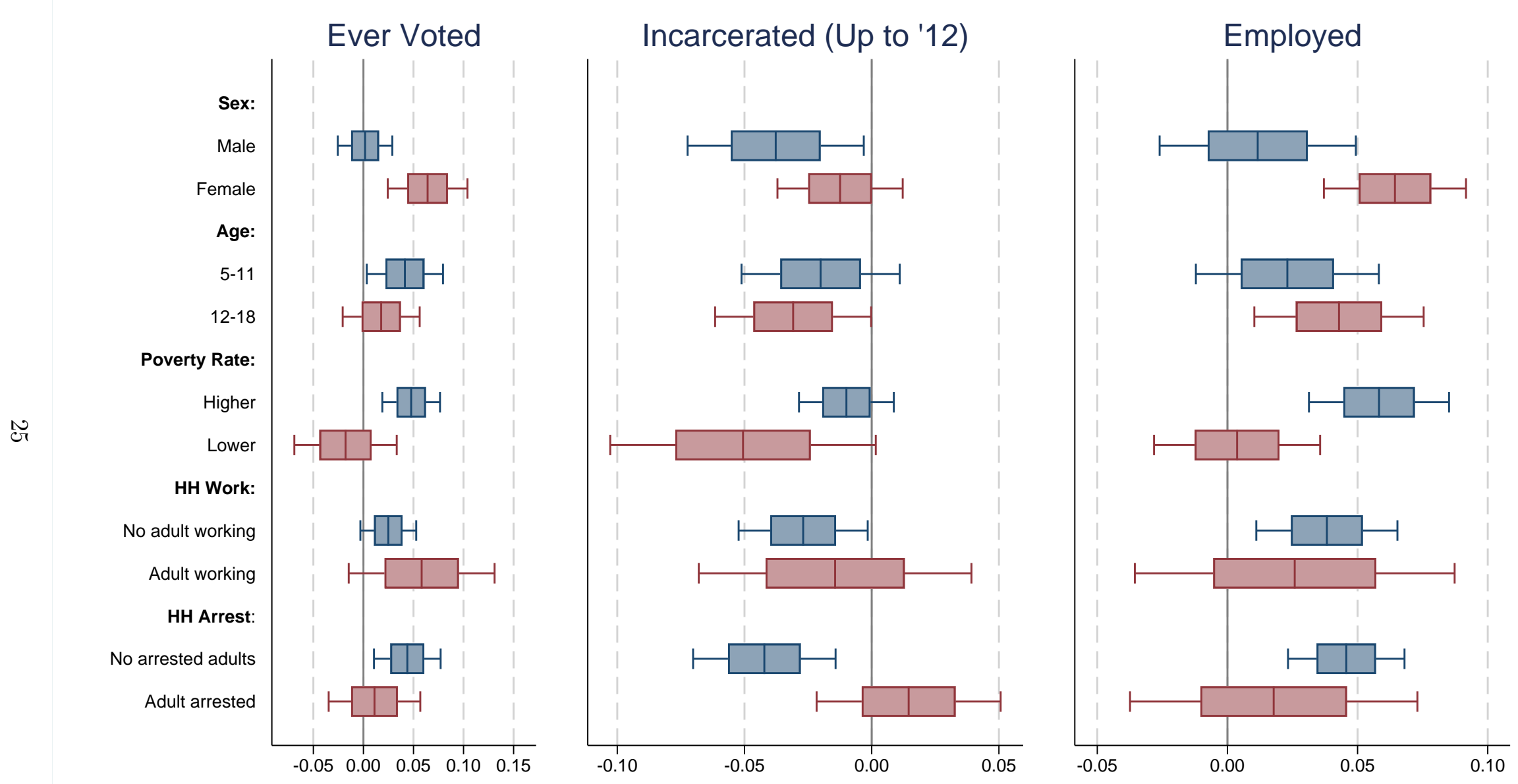

Notes: Rows present box and whisker plots for effects estimated separately for subgroups defined by baseline characteristics. The line at the center of each box is a point estimate for the estimated impact of demolition and relocation. The whiskers display the lower and upper ends of the 95-percent confidence interval. The left and right ends of the boxes display the points that are one standard error above and below the point estimate. 
Table 1: Comparison of Displaced and Non-displaced Adults and Children at Baseline (Prior to Demolition)

\begin{tabular}{|c|c|c|c|c|c|c|}
\hline & \multicolumn{3}{|c|}{ Children } & \multicolumn{3}{|c|}{ Adults (Parents) } \\
\hline & (1) & $(2)$ & (3) & $(4)$ & $(5)$ & (6) \\
\hline & $\begin{array}{c}\text { Control } \\
\text { Mean }\end{array}$ & $\begin{array}{l}\text { Diff.: Displaced-Non- } \\
\text { displaced, Within } \\
\text { Est. }\end{array}$ & $\mathrm{N}$ & $\begin{array}{c}\text { Control } \\
\text { Mean }\end{array}$ & $\begin{array}{l}\text { Diff.: Displaced-Non- } \\
\text { displaced, Within } \\
\text { Est. }\end{array}$ & $\mathrm{N}$ \\
\hline \multicolumn{7}{|l|}{ Demographics } \\
\hline Age & 10.650 & $\begin{array}{l}-0.104 \\
(0.140)\end{array}$ & 5,933 & 28.898 & $\begin{array}{c}0.706^{* *} \\
(0.284)\end{array}$ & 4,290 \\
\hline Male & 0.498 & $\begin{array}{c}0.001 \\
(0.013)\end{array}$ & 5,933 & 0.128 & $\begin{array}{c}0.000 \\
(0.010)\end{array}$ & 4,286 \\
\hline \multicolumn{7}{|c|}{ Arrests (Age $>13$ ) } \\
\hline Violent & 0.014 & $\begin{array}{c}0.003 \\
(0.007)\end{array}$ & 2,069 & 0.184 & $\begin{array}{l}-0.014 \\
(0.032)\end{array}$ & 4,178 \\
\hline Property & 0.011 & $\begin{array}{c}0.008 \\
(0.009)\end{array}$ & 2,069 & 0.158 & $\begin{array}{c}0.014 \\
(0.020)\end{array}$ & 4,178 \\
\hline Drug & 0.026 & $\begin{array}{l}-0.005 \\
(0.013)\end{array}$ & 2,069 & 0.166 & $\begin{array}{c}0.031 \\
(0.023)\end{array}$ & 4,178 \\
\hline Other & 0.021 & $\begin{array}{c}0.004 \\
(0.008)\end{array}$ & 2,069 & 0.228 & $\begin{array}{l}-0.014 \\
(0.028)\end{array}$ & 4,178 \\
\hline \multicolumn{7}{|l|}{ Schooling $^{\dagger}$} \\
\hline Enrolled CPS & 0.948 & $\begin{array}{c}0.003 \\
(0.014)\end{array}$ & 5,250 & & & \\
\hline Reading Score & -0.443 & $\begin{array}{c}0.024 \\
(0.074)\end{array}$ & 2,519 & & & \\
\hline Math Score & -0.449 & $\begin{array}{c}0.048 \\
(0.061)\end{array}$ & 2,502 & & & \\
\hline \multicolumn{7}{|l|}{ Employment ${ }^{\ddagger}$} \\
\hline Employed & & & & 0.172 & $\begin{array}{c}0.006 \\
(0.016)\end{array}$ & 4,265 \\
\hline Earnings & & & & $1,501.820$ & $\begin{array}{c}-68.514 \\
(197.028)\end{array}$ & 4,265 \\
\hline
\end{tabular}

Notes: This table analyzes baseline characteristics for displaced (treated) and non-displaced (control) individuals. The control mean statistics in Columns 1 and 4 refer to averages for non-displaced children. The mean difference between displaced and non-displaced children is reported in Columns 2 and 5. This difference is computed using a regression model where the baseline outcome (each row) is the dependent variable for individual $i$. The independent variables in the regression include an indicator for treatment (displaced) status and a set of project fixed effects. For the analysis of arrest and labor market outcomes, we exclude outliers (less than one percent). $\dagger$ Administrative data on employment begins in the first quarter of 1995. For individuals who experience a demolition in 1995, we use this quarter of earnings (scaled to an annual figure) to measure earnings prior to displacement because this quarter precedes demolition. $\$$ Education outcomes are only available for the main sample in Chyn (2018) which examines children age 7-18 at baseline. See Section 2 and Appendix B for further details. Statistical significance is denoted by: ${ }^{*} p<0.10,{ }^{* *} p<0.05$ and ${ }^{* * *} p<0.01$. 
Table 2: Impacts of Demolition and Relocation on Long-run Voting of Children

(1)

\begin{tabular}{ccc}
\hline \multirow{3}{*}{ Control Mean } & $\begin{array}{c}\text { Diff.: Displaced- } \\
\text { Non-displaced, } \\
\text { Within Est. }\end{array}$
\end{tabular}

\section{Voting:}

$\begin{array}{lccc}\text { Ever Voted, General } & 0.283 & \begin{array}{c}0.033^{* *} \\ (0.014)\end{array} & 5,933 \\ \text { Ever Voted, Primary } & 0.142 & \begin{array}{c}0.020^{*} \\ (0.010)\end{array} & 5,933 \\ \text { Voted General, 2016 } & 0.172 & 0.026^{* *} & 5,933 \\ & & (0.011) & 5,933 \\ \text { Voted General, 2012 } & 0.177 & 0.028^{* *} & (0.012) \\ \text { Voted General, 2008 } & 0.172 & 0.023^{* *} & 5,933 \\ \text { Share of Pres. Elections Voted } & 0.162 & (0.011) & 5,933 \\ & & 0.027^{* * *} & \\ \text { Registration: } & & (0.010) & 5,933 \\ \text { Registered } & 0.371 & 0.020^{*} & \\ \text { Registered, Non-partisan } & & (0.012) & 5,933 \\ \text { Registered, Republican } & 0.231 & 0.006 & 5,933 \\ \text { Registered, Democrat } & 0.004 & (0.012) & 5,933 \\ & & -0.002 & \end{array}$

Notes: This table analyzes adult voting outcomes for displaced (treated) and non-displaced (control) children. The control mean statistics in Column 1 refer to averages for non-displaced children. The mean difference between displaced and non-displaced children is reported in Column 2. This difference is computed using the regression model specified in Equation 1 where the voting outcome (each row) is the dependent variable for individual $i$. The independent variables in the regression include an indicator for treatment (displaced) status, a set of project fixed effects, and controls for sex and race. Statistical significance is denoted by: ${ }^{*} p<0.10,{ }^{* *} p<0.05$ and ${ }^{* * *} p<0.01$. 


\section{A Appendix Figures and Tables}

Figure A1: Density of Neighborhood Poverty After Demolition

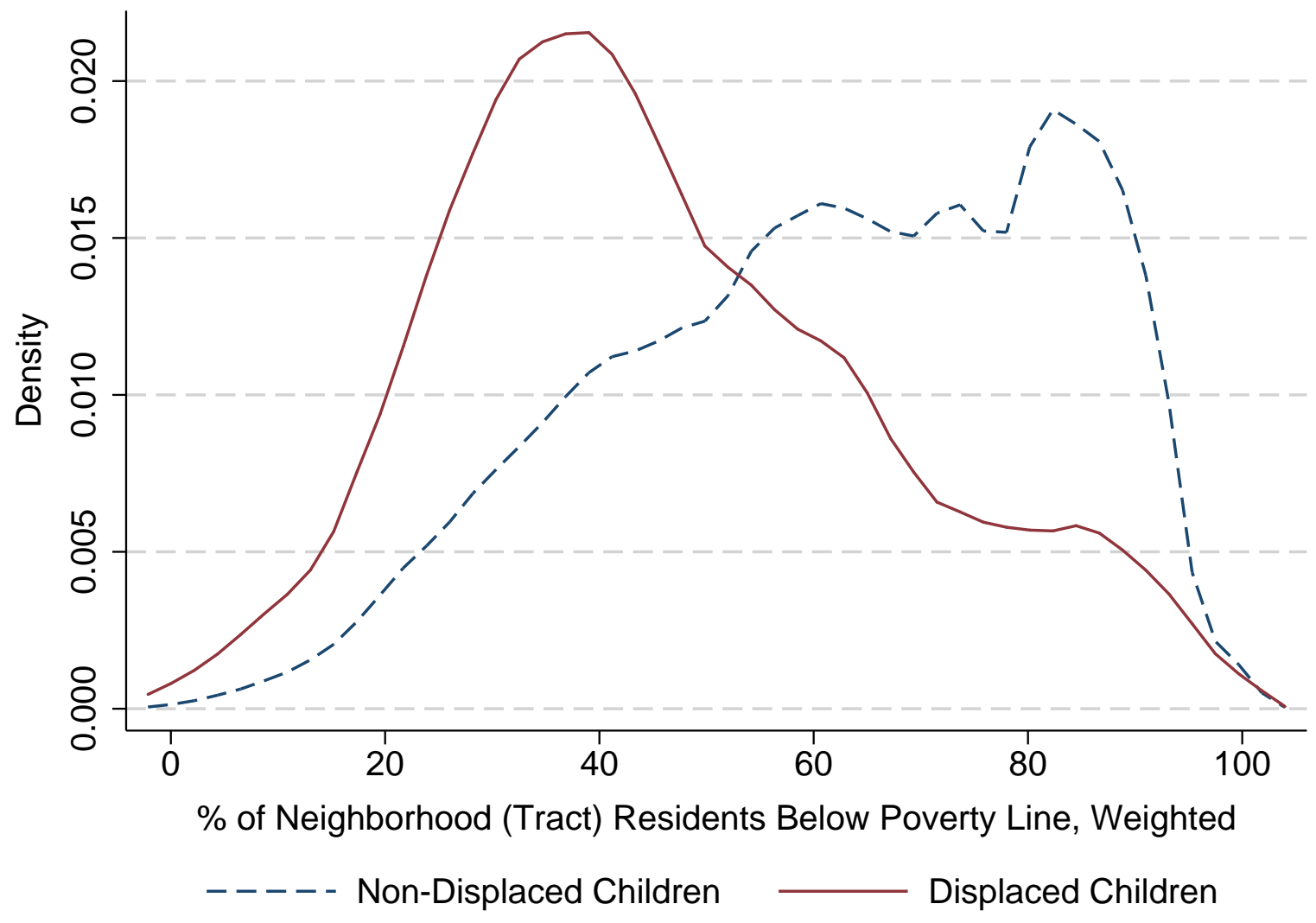

The figure shows statistics for the duration-weighted average poverty rate for each household in the sample $(N=$ 3,002 ). We compute the average over all post-demolition locations (up to 2009) for the household regardless of whether a child is still present. 
Figure A2: Impacts of Demolition and Relocation on Voting, Employment and Violent Arrests by Subgroup
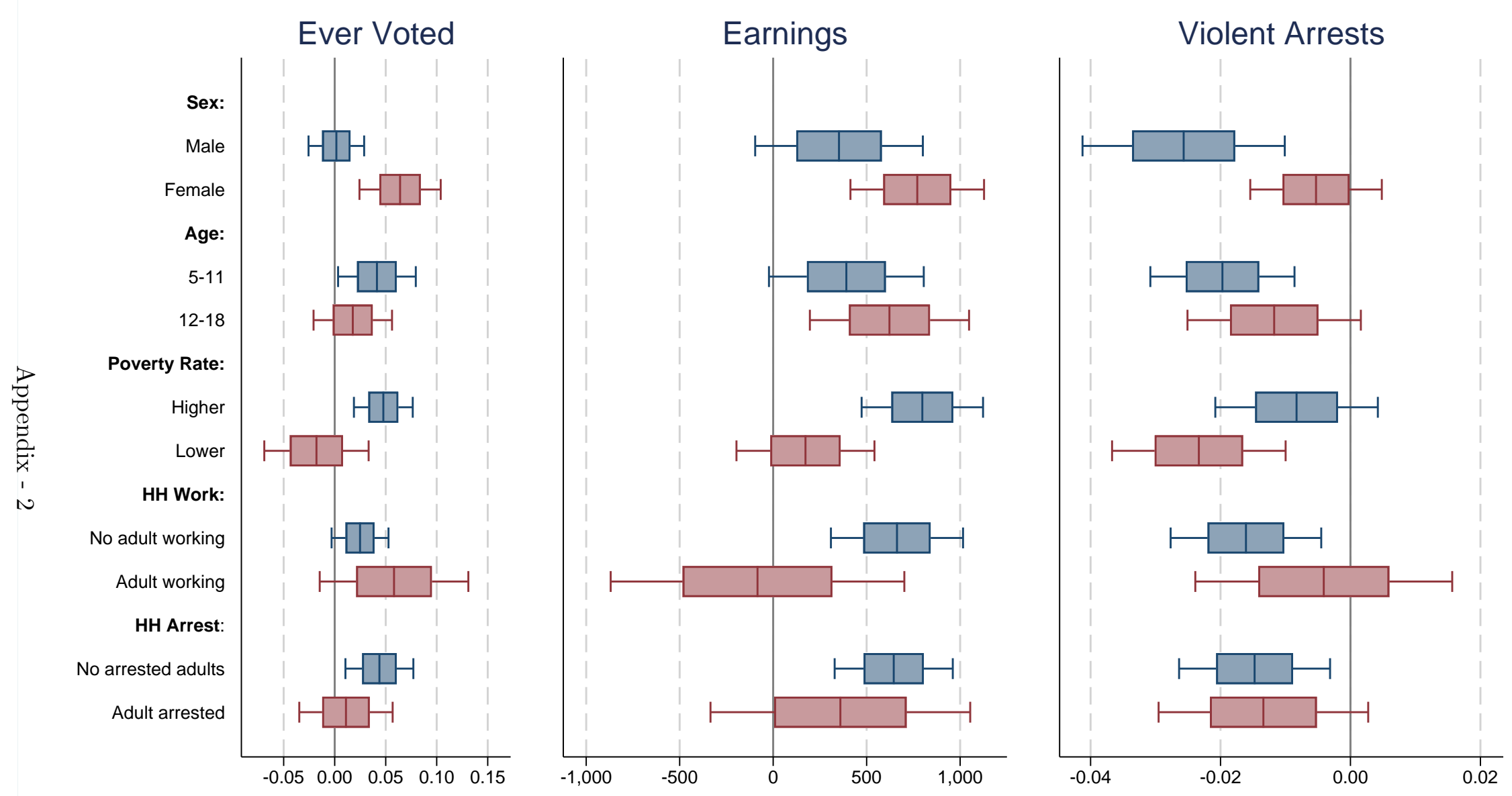

Notes: Rows present box and whisker plots for effects estimated separately for subgroups defined by baseline characteristics. The line at the center of each box is a point estimate for the estimated impact of demolition and relocation. The whiskers display the lower and upper ends of the 95 -percent confidence interval. The left and right ends of the boxes display the points that are one standard error above and below the point estimate. 
Table A1: Impacts of Demolition and Relocation on Neighborhood Characteristics, Three Years Post Displacement

\begin{tabular}{|c|c|c|c|}
\hline & (1) & $(2)$ & $(3)$ \\
\hline & Control Mean & $\begin{array}{l}\text { Diff.: Displaced- } \\
\text { Non-displaced, } \\
\text { Within Est. }\end{array}$ & $\mathrm{N}$ \\
\hline Has Address & 0.789 & $\begin{array}{c}0.011 \\
{[0.019]}\end{array}$ & 3,002 \\
\hline \multicolumn{4}{|l|}{ Only HHs with Address } \\
\hline Pct Black & 95.182 & $\begin{array}{c}-2.446^{* *} \\
{[1.085]}\end{array}$ & 2,297 \\
\hline Pct Below Poverty & 64.093 & $\begin{array}{c}-14.804^{* * *} \\
{[2.615]}\end{array}$ & 2,297 \\
\hline Violent Crime Rate & 69.327 & $\begin{array}{c}-25.033^{* * *} \\
{[5.374]}\end{array}$ & 2,253 \\
\hline Property Crime Rate & 103.331 & $\begin{array}{c}-24.235^{* *} \\
{[10.005]}\end{array}$ & 2,253 \\
\hline
\end{tabular}

Notes: The table reports analysis of location and neighborhood characteristics. The unit of analysis is a household with at least one child. Location is measured using address data from IDHS social assistance files. The control mean statistics in Columns 1 refers to averages for non-displaced households. Using the model from Equation 1, the mean difference between displaced and nondisplaced households three years after building demolition is reported in Columns 2 and 4 . Robust standard errors are clustered at the public housing building level. Statistical significance is denoted by: ${ }^{*} p<0.10,{ }^{* *} p<0.05$ and ${ }^{* * *} p<0.01$. 
Table A2: Impacts of Demolition and Relocation on Measures of Attrition

\begin{tabular}{|c|c|c|c|}
\hline & $(1)$ & $(2)$ & $(3)$ \\
\hline $\begin{array}{l}\text { Post } \\
\text { Demo. } \\
\text { Year }\end{array}$ & Control Mean & $\begin{array}{l}\text { Diff.: Displaced- } \\
\text { Non-displaced, } \\
\text { Within Est. }\end{array}$ & $\mathrm{N}$ \\
\hline 1 & 0.011 & $\begin{array}{c}-0.001 \\
(0.004)\end{array}$ & 5,933 \\
\hline 2 & 0.020 & $\begin{array}{c}0.002 \\
(0.007)\end{array}$ & 5,933 \\
\hline 3 & 0.031 & $\begin{array}{l}-0.003 \\
(0.008)\end{array}$ & 5,933 \\
\hline 4 & 0.038 & $\begin{array}{c}0.005 \\
(0.009)\end{array}$ & 5,933 \\
\hline 5 & 0.044 & $\begin{array}{c}0.010 \\
(0.011)\end{array}$ & 5,933 \\
\hline 6 & 0.054 & $\begin{array}{c}0.011 \\
(0.011)\end{array}$ & 5,933 \\
\hline 7 & 0.067 & $\begin{array}{c}0.001 \\
(0.013)\end{array}$ & 5,933 \\
\hline 8 & 0.079 & $\begin{array}{c}0.002 \\
(0.015)\end{array}$ & 5,933 \\
\hline 9 & 0.093 & $\begin{array}{l}-0.003 \\
(0.017)\end{array}$ & 5,933 \\
\hline 10 & 0.112 & $\begin{array}{l}-0.008 \\
(0.019)\end{array}$ & 5,933 \\
\hline 11 & 0.131 & $\begin{array}{l}-0.004 \\
(0.017)\end{array}$ & 5,933 \\
\hline 12 & 0.148 & $\begin{array}{c}0.001 \\
(0.024)\end{array}$ & 4,527 \\
\hline 13 & 0.185 & $\begin{array}{c}0.011 \\
(0.030)\end{array}$ & 4,527 \\
\hline 14 & 0.228 & $\begin{array}{c}0.002 \\
(0.028)\end{array}$ & 3,298 \\
\hline
\end{tabular}

Notes: This table presents tests for differential attrition based on the administrative data for children. We follow Grogger (2013) and construct a measure of attrition based on terminal runs of zeros for a given outcome in a panel of observations for each child. We do this for In each time period $t$ after demolition, we construct a measure of terminal zeros for employment, social assistance receipt (foodstamps, TANF or Medicaid), arrests and imprisonment. We aggregate across these outcomes to create a single measure of whether an individual in year $t$ has a terminal string of zeros (up to 2009). For example, the first entry of Column 1 shows that 1.1 percent of the non-displaced children began a terminal run of zeros for all outcomes in the first year after demolition (up to 2009). Column 2 tests whether displaced and non-displaced youth have detectably different rates of attrition using Equation 1 . Note that the sample size changes in post demolition years 12, 13 and 14 because some children are displaced in 1998 so they only have 11 years of post-demolition data. 
Table A3: Spillover Test Results

\begin{tabular}{|c|c|c|c|c|}
\hline & $(1)$ & $(2)$ & $(3)$ & $(4)$ \\
\hline & $\begin{array}{c}\text { Control } \\
\text { Mean }\end{array}$ & $\begin{array}{c}\text { Diff.: } \\
\text { Displaced-Far, } \\
\text { Within Est. }\end{array}$ & $\begin{array}{c}\text { Diff: } \\
\text { Near-Far, } \\
\text { Within Est. }\end{array}$ & $\mathrm{N}$ \\
\hline \multicolumn{5}{|l|}{ Voting: } \\
\hline Ever Voted, General & 0.273 & $\begin{array}{c}0.039^{* *} \\
(0.018)\end{array}$ & $\begin{array}{c}0.008 \\
(0.017)\end{array}$ & 5,933 \\
\hline Ever Voted, Primary & 0.143 & $\begin{array}{c}0.018 \\
(0.013)\end{array}$ & $\begin{array}{l}-0.003 \\
(0.012)\end{array}$ & 5,933 \\
\hline Voted General, 2016 & 0.159 & $\begin{array}{c}0.037^{* *} \\
(0.015)\end{array}$ & $\begin{array}{c}0.015 \\
(0.015)\end{array}$ & 5,933 \\
\hline Voted General, 2012 & 0.172 & $\begin{array}{l}0.030^{*} \\
(0.017)\end{array}$ & $\begin{array}{c}0.004 \\
(0.017)\end{array}$ & 5,933 \\
\hline Voted General, 2008 & 0.165 & $\begin{array}{c}0.027^{*} \\
(0.016)\end{array}$ & $\begin{array}{c}0.007 \\
(0.014)\end{array}$ & 5,933 \\
\hline Share of Pres. Elections Voted & 0.154 & $\begin{array}{c}0.033^{* *} \\
(0.014)\end{array}$ & $\begin{array}{c}0.009 \\
(0.013)\end{array}$ & 5,933 \\
\hline \multicolumn{5}{|l|}{ Registration: } \\
\hline Registered & 0.356 & $\begin{array}{c}0.033^{* *} \\
(0.014)\end{array}$ & $\begin{array}{c}0.018 \\
(0.015)\end{array}$ & 5,933 \\
\hline Registered, Non-partisan & 0.217 & $\begin{array}{c}0.019 \\
(0.015)\end{array}$ & $\begin{array}{c}0.018 \\
(0.015)\end{array}$ & 5,933 \\
\hline Registered, Republican & 0.005 & $\begin{array}{l}-0.002 \\
(0.002)\end{array}$ & $\begin{array}{l}-0.001 \\
(0.002)\end{array}$ & 5,933 \\
\hline Registered, Democrat & 0.133 & $\begin{array}{c}0.016 \\
(0.012)\end{array}$ & $\begin{array}{c}0.000 \\
(0.011)\end{array}$ & 5,933 \\
\hline
\end{tabular}

Notes: This table presents tests of spillovers using Equation 2 from Section 3. The independent variables in the regression model include an indicator for treatment (displaced) status, an indicator for living in a public housing building that borders (is adjacent to) a demolition targetted building, a set of project fixed effects, and controls for sex and race. The omitted group in the regression is the set of children living in stable buildings located in the "far" buildings that were not adjacent to demolished buildings. The control mean statistics in Column 1 refer to the averages for non-displaced individuals living in the group of far buildings. Statistical significance is denoted by: ${ }^{*}$ $p<0.10,{ }^{* *} p<0.05$ and ${ }^{* * *} p<0.01$. 
Table A4: Impacts of Demolition and Relocation Incarceration

\begin{tabular}{lccc}
\hline \hline & $(1)$ & $(2)$ & $(3)$ \\
\cline { 2 - 4 } & Control Mean & $\begin{array}{c}\text { Diff.: Displaced- } \\
\text { Non-displaced, } \\
\text { Within Est. }\end{array}$ & $\mathrm{N}$ \\
Ever Incarcerated (Up to 2012) & 0.155 & $-0.025^{* *}$ & 5,933 \\
Incarcerated, 2010 & 0.043 & -0.008 & 5,933 \\
Incarcerated, 2008 & 0.049 & {$[0.007]$} & 5,933 \\
Incarcerated, 2004 & 0.044 & -0.007 & 3,364 \\
Share of Pres. Election Years in Jail & 0.047 & -0.012 & 5,933 \\
& & $-0.008]$ & \\
\hline \hline
\end{tabular}

Notes: This table analyzes incarceration outcomes for displaced (treated) and non-displaced (control) children. The control mean statistics in Column 1 refer to averages for non-displaced children. The mean difference between displaced and non-displaced children is reported in Column 2. This difference is computed using the regression model specified in Equation 1 where the voting outcome (each row) is the dependent variable for individual $i$. The independent variables in the regression include an indicator for treatment (displaced) status, a set of project fixed effects, and controls for sex and race. Statistical significance is denoted by: ${ }^{*} p<0.10,{ }^{* *} p<0.05$ and ${ }^{* * *} p<0.01$. 
Table A5: Impacts of Demolition and Relocation on Voting of Parents

\begin{tabular}{|c|c|c|c|}
\hline & $(1)$ & $(2)$ & $(3)$ \\
\hline & Control Mean & $\begin{array}{l}\text { Diff.: Displaced- } \\
\text { Non-displaced, } \\
\text { Within Est. }\end{array}$ & $\mathrm{N}$ \\
\hline \multicolumn{4}{|l|}{ Voting: } \\
\hline Ever Voted, General & 0.356 & $\begin{array}{c}0.012 \\
(0.012)\end{array}$ & 4,290 \\
\hline Ever Voted, Primary & 0.251 & $\begin{array}{c}0.011 \\
(0.012)\end{array}$ & 4,290 \\
\hline Voted General, 2016 & 0.265 & $\begin{array}{c}0.005 \\
(0.015)\end{array}$ & 4,290 \\
\hline Voted General, 2012 & 0.268 & $\begin{array}{c}0.001 \\
(0.014)\end{array}$ & 4,290 \\
\hline Voted General, 2008 & 0.260 & $\begin{array}{c}0.005 \\
(0.011)\end{array}$ & 4,290 \\
\hline Share of Pres. Elections Voted, General & 0.244 & $\begin{array}{c}0.000 \\
(0.010)\end{array}$ & 4,290 \\
\hline \multicolumn{4}{|l|}{ Registration: } \\
\hline Registered & 0.389 & $\begin{array}{c}0.030^{* *} \\
(0.013)\end{array}$ & 4,290 \\
\hline Registered, Non-partisan & 0.128 & $\begin{array}{l}0.021^{*} \\
(0.011)\end{array}$ & 4,290 \\
\hline Registered, Republican & 0.003 & $\begin{array}{c}0.002 \\
(0.002)\end{array}$ & 4,290 \\
\hline Registered, Democrat & 0.258 & $\begin{array}{c}0.007 \\
(0.011)\end{array}$ & 4,290 \\
\hline
\end{tabular}

Notes: This table analyzes adult voting outcomes for displaced (treated) and non-displaced (control) parents. The control mean statistics in Column 1 refer to averages for non-displaced parents. The mean difference between displaced and non-displaced children is reported in Column 2. This difference is computed using the regression model specified in Equation 1 where the voting outcome (each row) is the dependent variable for individual $i$. The independent variables in the regression include an indicator for treatment (displaced) status, a set of project fixed effects, and controls for sex and race. Statistical significance is denoted by: ${ }^{*} p<0.10,{ }^{* *} p<0.05$ and ${ }^{* * *} p<0.01$. 
Table A6: Impacts of Demolition and Relocation on Voting by Subgroup

\begin{tabular}{|c|c|c|c|c|}
\hline & $(1)$ & $(2)$ & $(3)$ & $(4)$ \\
\hline Subgroup & $\begin{array}{l}\text { Fraction of } \\
\text { All Children }\end{array}$ & Control Mean & $\begin{array}{l}\text { Diff.: Displaced- } \\
\text { Non-displaced, } \\
\text { Within Est. }\end{array}$ & $\mathrm{N}$ \\
\hline All & 1.00 & 0.283 & $\begin{array}{c}0.033^{* *} \\
(0.014)\end{array}$ & 5,933 \\
\hline \multicolumn{5}{|l|}{ Sex } \\
\hline Male & 0.49 & 0.193 & $\begin{array}{c}0.002 \\
(0.014)\end{array}$ & 2,939 \\
\hline Female & 0.51 & 0.371 & $\begin{array}{l}0.064^{* *} \\
(0.020)\end{array}$ & 2,994 \\
\hline \multicolumn{5}{|l|}{ Age at Baseline } \\
\hline $5-11$ & 0.58 & 0.261 & $\begin{array}{c}0.041^{* *} \\
(0.019)\end{array}$ & 3,464 \\
\hline $12-18$ & 0.42 & 0.316 & $\begin{array}{c}0.018 \\
(0.020)\end{array}$ & 2,469 \\
\hline \multicolumn{5}{|l|}{ Poverty Rate } \\
\hline Higher & 0.80 & 0.277 & $\begin{array}{c}0.048^{* *} \\
(0.015)\end{array}$ & 4,760 \\
\hline Lower & 0.20 & 0.304 & $\begin{array}{l}-0.018 \\
(0.026)\end{array}$ & 1,173 \\
\hline \multicolumn{5}{|l|}{ HH Adult Employment } \\
\hline No Working Adults & 0.83 & 0.281 & $\begin{array}{l}0.025^{*} \\
(0.014)\end{array}$ & 4,887 \\
\hline$>0$ Working Adults & 0.17 & 0.290 & $\begin{array}{c}0.058 \\
(0.037)\end{array}$ & 1,046 \\
\hline \multicolumn{5}{|l|}{ HH Past Arrests } \\
\hline No Adults with Arrest(s) & 0.69 & 0.279 & $\begin{array}{c}0.044^{* *} \\
(0.017)\end{array}$ & 4,061 \\
\hline$>0$ Adults with Arrest(s) & 0.31 & 0.291 & $\begin{array}{c}0.011 \\
(0.023)\end{array}$ & 1,872 \\
\hline
\end{tabular}

Notes: Subgroups are based on baseline (the year prior to relocation due to demolition) characteristics. The control mean statistics in Column 2 refer to averages for non-displaced individuals. The specification includes indicators for treatment interacted with subgroup membership indicators and project fixed effects. Results by baseline neighborhood poverty rate are based on dividing the sample into a group of children residing in "higher poverty projects" where the poverty rate was 87 percent and a group of children residing in "lower poverty projects" where the poverty rate was 66 percent. Robust standard errors are clustered at the public housing building level. Statistical significance is denoted by: ${ }^{*} p<0.10,{ }^{* *} p<0.05$ and ${ }^{* *} p<0.01$. 
Table A7: Impacts of Demolition and Relocation on Incarceration by Subgroup

\begin{tabular}{|c|c|c|c|c|}
\hline & $(1)$ & $(2)$ & $(3)$ & $(4)$ \\
\hline Subgroup & $\begin{array}{l}\text { Fraction of } \\
\text { All Children }\end{array}$ & Control Mean & $\begin{array}{l}\text { Diff.: Displaced- } \\
\text { Non-displaced, } \\
\text { Within Est. }\end{array}$ & $\mathrm{N}$ \\
\hline All & 1.00 & 0.155 & $\begin{array}{c}-0.025^{* *} \\
(0.012)\end{array}$ & 5,933 \\
\hline \multicolumn{5}{|l|}{ Sex } \\
\hline Male & 0.50 & 0.260 & $\begin{array}{c}-0.038^{* *} \\
(0.018)\end{array}$ & 2,939 \\
\hline Female & 0.50 & 0.051 & $\begin{array}{l}-0.012 \\
(0.013)\end{array}$ & 2,994 \\
\hline \multicolumn{5}{|l|}{ Age at Baseline } \\
\hline $5-11$ & 0.58 & 0.130 & $\begin{array}{l}-0.020 \\
(0.016)\end{array}$ & 3,464 \\
\hline $12-18$ & 0.42 & 0.193 & $\begin{array}{c}-0.031^{*} \\
(0.016)\end{array}$ & 2,469 \\
\hline \multicolumn{5}{|l|}{ Poverty Rate } \\
\hline Higher & 0.80 & 0.151 & $\begin{array}{l}-0.010 \\
(0.010)\end{array}$ & 4,760 \\
\hline Lower & 0.20 & 0.172 & $\begin{array}{l}-0.051^{*} \\
(0.027)\end{array}$ & 1,173 \\
\hline \multicolumn{5}{|l|}{ HH Adult Employment } \\
\hline No Working Adults & 0.82 & 0.155 & $\begin{array}{c}-0.027^{* *} \\
(0.013)\end{array}$ & 4,887 \\
\hline$>0$ Working Adults & 0.18 & 0.154 & $\begin{array}{l}-0.014 \\
(0.027)\end{array}$ & 1,046 \\
\hline \multicolumn{5}{|l|}{ HH Past Arrests } \\
\hline No Adults with Arrest(s) & 0.68 & 0.153 & $\begin{array}{c}-0.042^{* *} \\
(0.014)\end{array}$ & 4,061 \\
\hline$>0$ Adults with Arrest(s) & 0.32 & 0.161 & $\begin{array}{c}0.015 \\
(0.018)\end{array}$ & 1,872 \\
\hline
\end{tabular}

Notes: Subgroups are based on baseline (the year prior to relocation due to demolition) characteristics. The control mean statistics in Column 2 refer to averages for non-displaced individuals. The specification includes indicators for treatment interacted with subgroup membership indicators and project fixed effects. Results by baseline neighborhood poverty rate are based on dividing the sample into a group of children residing in "higher poverty projects" where the poverty rate was 87 percent and a group of children residing in "lower poverty projects" where the poverty rate was 66 percent. Robust standard errors are clustered at the public housing building level. Statistical significance is denoted by: ${ }^{*} p<0.10,{ }^{* *} p<0.05$ and ${ }^{* * *} p<0.01$. 
Table A8: Impacts of Demolition and Relocation on Employment by Subgroup

\begin{tabular}{|c|c|c|c|c|}
\hline & $(1)$ & $(2)$ & $(3)$ & $(4)$ \\
\hline Subgroup & $\begin{array}{l}\text { Fraction of } \\
\text { All Children }\end{array}$ & Control Mean & $\begin{array}{l}\text { Diff.: Displaced- } \\
\text { Non-displaced, } \\
\text { Within Est. }\end{array}$ & $\mathrm{N}$ \\
\hline All & 1.00 & 0.415 & $\begin{array}{c}0.037^{* * *} \\
(0.013)\end{array}$ & 6,130 \\
\hline \multicolumn{5}{|l|}{ Sex } \\
\hline Male & 0.49 & 0.324 & $\begin{array}{c}0.012 \\
(0.019)\end{array}$ & 3,023 \\
\hline Female & 0.51 & 0.500 & $\begin{array}{c}0.064^{* *} \\
(0.014)\end{array}$ & 3,107 \\
\hline \multicolumn{5}{|l|}{ Age at Baseline } \\
\hline $5-11$ & 0.58 & 0.384 & $\begin{array}{c}0.023 \\
(0.018)\end{array}$ & 3,562 \\
\hline $12-18$ & 0.42 & 0.431 & $\begin{array}{l}0.043^{* *} \\
(0.017)\end{array}$ & 2,568 \\
\hline \multicolumn{5}{|l|}{ Poverty Rate } \\
\hline Higher & 0.80 & 0.410 & $\begin{array}{c}0.058^{* *} \\
(0.014)\end{array}$ & 4,930 \\
\hline Lower & 0.20 & 0.438 & $\begin{array}{l}0.004 \\
(0.016)\end{array}$ & 1,200 \\
\hline \multicolumn{5}{|l|}{ HH Adult Employment } \\
\hline No Working Adults & 0.83 & 0.408 & $\begin{array}{c}0.038^{* *} \\
(0.014)\end{array}$ & 5,065 \\
\hline$>0$ Working Adults & 0.17 & 0.459 & $\begin{array}{c}0.026 \\
(0.031)\end{array}$ & 1,065 \\
\hline \multicolumn{5}{|l|}{ HH Past Arrests } \\
\hline No Adults with Arrest(s) & 0.69 & 0.424 & $\begin{array}{c}0.046^{* *} \\
(0.011)\end{array}$ & 4,223 \\
\hline$>0$ Adults with Arrest(s) & 0.31 & 0.394 & $\begin{array}{c}0.018 \\
(0.028)\end{array}$ & 1,907 \\
\hline
\end{tabular}

Notes: Subgroups are based on baseline (the year prior to relocation due to demolition) characteristics. The control mean statistics in Column 2 refer to averages for non-displaced individuals. The specification includes indicators for treatment interacted with subgroup membership indicators and project fixed effects. Results by baseline neighborhood poverty rate are based on dividing the sample into a group of children residing in "higher poverty projects" where the poverty rate was 87 percent and a group of children residing in "lower poverty projects" where the poverty rate was 66 percent. Robust standard errors are clustered at the public housing building level. Statistical significance is denoted by: ${ }^{*} p<0.10,{ }^{* *} p<0.05$ and ${ }^{* * *} p<0.01$. Note that the analysis omits some observations (less than one percent) that are outliers in the distribution of earnings. 
Table A9: Impacts of Demolition and Relocation on Earnings by Subgroup

\begin{tabular}{|c|c|c|c|c|}
\hline & (1) & $(2)$ & $(3)$ & $(4)$ \\
\hline Subgroup & $\begin{array}{l}\text { Fraction of } \\
\text { All Children }\end{array}$ & Control Mean & $\begin{array}{l}\text { Diff.: Displaced- } \\
\text { Non-displaced, } \\
\text { Within Est. }\end{array}$ & $\mathrm{N}$ \\
\hline All & 1.00 & $3,628.968$ & $\begin{array}{c}549.582^{* * *} \\
(149.769)\end{array}$ & 6,130 \\
\hline \multicolumn{5}{|l|}{ Sex } \\
\hline Male & 0.49 & $2,879.610$ & $\begin{array}{c}352.223 \\
(228.832)\end{array}$ & 3,023 \\
\hline Female & 0.51 & $4,322.790$ & $\begin{array}{l}770.832^{* *} \\
(182.305)\end{array}$ & 3,107 \\
\hline \multicolumn{5}{|l|}{ Age at Baseline } \\
\hline $5-11$ & 0.58 & $2,551.173$ & $\begin{array}{l}391.472^{*} \\
(211.237)\end{array}$ & 3,562 \\
\hline $12-18$ & 0.42 & $4,182.590$ & $\begin{array}{l}622.095^{* *} \\
(217.170)\end{array}$ & 2,568 \\
\hline \multicolumn{5}{|l|}{ Poverty Rate } \\
\hline Higher & 0.80 & $3,512.065$ & $\begin{array}{c}797.933 * * \\
(165.706)\end{array}$ & 4,930 \\
\hline Lower & 0.20 & $4,092.636$ & $\begin{array}{c}172.813 \\
(188.263)\end{array}$ & 1,200 \\
\hline \multicolumn{5}{|l|}{ HH Adult Employment } \\
\hline No Working Adults & 0.83 & $3,522.035$ & $\begin{array}{c}662.311^{* *} \\
(180.273)\end{array}$ & 5,065 \\
\hline$>0$ Working Adults & 0.17 & $4,264.922$ & $\begin{array}{c}-83.673 \\
(400.657)\end{array}$ & 1,065 \\
\hline \multicolumn{5}{|l|}{ HH Past Arrests } \\
\hline No Adults with Arrest(s) & 0.69 & $3,799.574$ & $\begin{array}{c}644.858^{* *} \\
(161.199)\end{array}$ & 4,223 \\
\hline$>0$ Adults with Arrest(s) & 0.31 & $3,215.531$ & $\begin{array}{c}359.405 \\
(354.327)\end{array}$ & 1,907 \\
\hline
\end{tabular}

Notes: Subgroups are based on baseline (the year prior to relocation due to demolition) characteristics. The control mean statistics in Column 2 refer to averages for non-displaced individuals. The specification includes indicators for treatment interacted with subgroup membership indicators and project fixed effects. Results by baseline neighborhood poverty rate are based on dividing the sample into a group of children residing in "higher poverty projects" where the poverty rate was 87 percent and a group of children residing in "lower poverty projects" where the poverty rate was 66 percent. Robust standard errors are clustered at the public housing building level. Statistical significance is denoted by: ${ }^{*} p<0.10,{ }^{* *} p<0.05$ and ${ }^{* * *} p<0.01$. Note that the analysis omits some observations (less than one percent) that are outliers in the distribution of earnings. 
Table A10: Impacts of Demolition and Relocation on Violent Arrests by Subgroup

\begin{tabular}{|c|c|c|c|c|}
\hline & (1) & $(2)$ & $(3)$ & $(4)$ \\
\hline Subgroup & $\begin{array}{l}\text { Fraction of } \\
\text { All Children }\end{array}$ & Control Mean & $\begin{array}{l}\text { Diff.: Displaced- } \\
\text { Non-displaced, } \\
\text { Within Est. }\end{array}$ & $\mathrm{N}$ \\
\hline All & 1.00 & 0.064 & $\begin{array}{c}-0.014^{* *} \\
(0.005)\end{array}$ & 6,135 \\
\hline \multicolumn{5}{|l|}{ Sex } \\
\hline Male & 0.49 & 0.099 & $\begin{array}{c}-0.026^{* *} \\
(0.008)\end{array}$ & 3,024 \\
\hline Female & 0.51 & 0.031 & $\begin{array}{l}-0.005 \\
(0.005)\end{array}$ & 3,111 \\
\hline \multicolumn{5}{|l|}{ Age at Baseline } \\
\hline $5-11$ & 0.58 & 0.072 & $\begin{array}{c}-0.020^{* *} \\
(0.006)\end{array}$ & 3,565 \\
\hline $12-18$ & 0.42 & 0.060 & $\begin{array}{c}-0.012^{*} \\
(0.007)\end{array}$ & 2,570 \\
\hline \multicolumn{5}{|l|}{ Poverty Rate } \\
\hline Higher & 0.80 & 0.064 & $\begin{array}{l}-0.008 \\
(0.006)\end{array}$ & 4,935 \\
\hline Lower & 0.20 & 0.063 & $\begin{array}{c}-0.023^{* *} \\
(0.007)\end{array}$ & 1,200 \\
\hline \multicolumn{5}{|l|}{ HH Adult Employment } \\
\hline No Working Adults & 0.83 & 0.066 & $\begin{array}{c}-0.016^{* *} \\
(0.006)\end{array}$ & 5,070 \\
\hline$>0$ Working Adults & 0.17 & 0.051 & $\begin{array}{l}-0.004 \\
(0.010)\end{array}$ & 1,065 \\
\hline \multicolumn{5}{|l|}{ HH Past Arrests } \\
\hline No Adults with Arrest(s) & 0.69 & 0.062 & $\begin{array}{c}-0.015^{* *} \\
(0.006)\end{array}$ & 4,226 \\
\hline$>0$ Adults with Arrest(s) & 0.31 & 0.068 & $\begin{array}{l}-0.013 \\
(0.008)\end{array}$ & 1,909 \\
\hline
\end{tabular}

Notes: Subgroups are based on baseline (the year prior to relocation due to demolition) characteristics. The control mean statistics in Column 2 refer to averages for non-displaced individuals. The specification includes indicators for treatment interacted with subgroup membership indicators and project fixed effects. Results by baseline neighborhood poverty rate are based on dividing the sample into a group of children residing in "higher poverty projects" where the poverty rate was 87 percent and a group of children residing in "lower poverty projects" where the poverty rate was 66 percent. Robust standard errors are clustered at the public housing building level. Statistical significance is denoted by: ${ }^{*} p<0.10,{ }^{* *} p<0.05$ and ${ }^{* * *} p<0.01$. 


\section{B Description of Data, Sample and Linking Process}

The analysis in this paper is based on studying a sample of public housing residents that have been linked to the 2019 Illinois (IL) voterfile purchased from the vendor L2, Inc., a non-partisan firm that supplies voter data to candidates, political parties, and others. The process for creating this data consists of two main steps:

1. Cleaning the sample of public housing residents: Chyn (2018) created a sample of public housing residents (adults and children) to study long-run impacts of public housing demolition on labor market and criminal justice outcomes. As summarized in Section 3 and Chyn (2018), this sample was created by matching the street addresses of 53 demolitionaffected public housing buildings (including demolished and non-demolished buildings) with social assistance case files from the Illinois Department of Human Services (IDHS). This IDHS data is a list of all Cook County (which includes Chicago) cases for beneficiaries who received social assistance services (TANF, Foodstamps or Medicaid) from 1994 to 1997. These case files are associated with 992,729 individuals (463,542 are recipients ("grantees") while 529,187 are individuals living in the same household). With the merged data, we look for social assistance cases where the household (grantees and the other individuals listed on a case) had an address matched to a demolition affected public housing address in the year prior to building closure. Note that this process includes identifying individuals living in the set of non-demolished buildings in the year before a building closure for demolition occurs in their housing project. This focus on the year before building closure ensures the definition for the sample of child households is unrelated to any impact that demolition has on public assistance participation. The process results in a preliminary sample that contains 6,135 children ages 5 to 18 that lived in public housing in the year before demolition. To link this data to voting records, we define a matching set of variables as first name, last name and date of birth. There are 202 children (3.3 percent) who have non-unique or missing information in terms of the matching set of variables. We drop these children with duplicated matching variable information. The remaining 5,933 children are the main sample for the voting analysis in this paper.

2. Linking public housing residents to the 2019 IL voterfile: We link the sample of 5,933

Appendix - 13 
public housing children to the Illinois voter file provided by L2, Inc. Voting data from L2 has been used in prior research (Velez and Newman, 2019; Yoder, 2019; Enamorado et al., 2019). L2 obtained a snapshot of the voter file on July 1, 2019 directly from the Illinois Secretary of State office. This file includes voter registration information for the full state, as well as voter turnout in the 2000-2018 general and primary elections. In addition to the voter file, L2 supplements this data with additional commercial fields, though for the purposes of this paper we just use fields provided by the State (as well as an L2-modeled party affiliation variable). Specifically, we use the full name, date of birth, indicators for whether the individual voted in each national election, and a modeled variable indicating the party of the voter. ${ }^{19}$ Both L2 and the State routinely clean the voter file and remove individuals who are either deceased or moved (based on the National Change of Address). As an example, we will not observe an individual in the voter file who voted in Illinois in 2014, but moved anytime between 2015 to 2019 (and whose move was recorded in the National Change of Address). To link the sample of public housing children and the voting records, we use first name, last name and date of birth. Prior studies also use name and date of birth to link that link administrative records and voting records. For example, Baicker and Finkelstein (2018) use full name, date of birth and gender to link data from the Oregon Health Experiment to voting records. Akee et al. (2018) use first name, last name and date of birth to link the Great Smoky Mountains Study survey data to voting records. Holbein (2017) use first name, last name and birthday to match individuals who participated in the Fast Track intervention to voter records. Our linking based on first name, last name and date of birth results in 2,227 public housing children (37 percent) that can be linked to the $2019 \mathrm{IL}$ voterfile. ${ }^{20,21}$ There are 6 children who link to two distinct

\footnotetext{
${ }^{19}$ Since Illinois does not record the party of a voter, L2 provides a modeled field based on voting in partisan primaries. Specifically, they use the most recent even year primary in which a voter cast a partisan ballot. For example, if an individual voted in the Democrat primary in 2018 and the Republican primary in 2016, they will be recorded as a Democrat. If the voter has participated in no primaries, then she will be recorded as Non-Partisan.

${ }^{20}$ The sample of public housing children are ages 29 to 42 in 2019. As one point of comparison, the voter registration rate for persons ages 25-34 in Illinois is 55.5 percent (U.S. Census, 2018). While a match rate of 37 percent is lower than the statewide voter registration rate, it is important to note the sample is composed of minority children from low-income households. Prior research shows that voting and political behavior in the U.S. is strongly related with income (Erikson, 2015). Moreover, black voters living poor neighborhoods are much less likely to be politically active relative to similar poor residents of more affluent neighborhoods (Cohen and Dawson, 1993; Alex-Assensoh, 1998).

${ }^{21} \mathrm{We}$ also explored an alternative linking based on probabilistic matching methods. The main drawback of this approach is that we will obtain false matches. Using this alternative linking process, we obtain a match rate of 44 percent. Based on this alternative sample, we reassuringly find similar estimated impacts on voting outcomes. For example, we find that the impact of demolition and relocation is a positive 3.2 percentage points impact on the likelihood of ever voting in a general election (2000-2018). In our main estimates (based on exact matching), the
} 
registration records in the 2019 IL voterfile. For these 6 cases, we randomly select one of the two linked records in the 2019 IL voterfile to retain for our analysis.

corresponding point estimate is 3.3 percentage points.

Appendix - 15 


\section{Details on Attrition Measures}

In Section 3.3, we discuss analysis of attrition. Specifically, we follow Grogger (2013) and impute attrition $A$ using various administrative sources. This measure of attrition is straightforward. Permanent attrition at time $t$ implies that an outcome is zero subsequently (i.e. $Y_{i, t+j}=0 \forall j \quad \in$ $\{1, \ldots, T-t\}$, where $Y$ is an administrative data outcome and $T$ denotes the last unit of time in the data). For a single outcome $k$, we measure attrition by creating a binary indicator of a $d$-period run of zeros as:

$$
a_{i, t}^{k}(d)=\mathbf{1}\left(\sum_{j=0}^{d-1} Y_{i, t+j}^{k}=0\right) .
$$

Administrative data for the $K$-many outcomes available across administrative sources can be pooled and attrition can measured as:

$$
a_{i, t}(d)=\mathbf{1}\left(\sum_{j=1}^{K} a_{d}^{k}=K\right) .
$$

In what follows, we use the following compact notation: $a_{i, t}^{k} \equiv a_{i, t}^{k}(d)$ and $a_{i, t}(d) \equiv a_{i, t}$.

Appendix Table A2 reports analysis of attrition. The measure is based on pooling separate measures of attrition using data on employment, social assistance receipt (foodstamps, TANF or Medicaid), arrests and imprisonment. We measure attrition in each year $t$ after demolition (up to 2009). For example, the first entry of Column 1 shows that 1.1 percent of the non-displaced children began a terminal run of zeros for all outcomes in the first year after demolition (up to 2009). Column 2 tests whether displaced and non-displaced youth have detectably different rates of attrition using Equation 1. Note that the sample size changes in post demolition years 12, 13 and 14 because some children are displaced in 1998 so they only have 11 years of post-demolition data. 